\title{
COMPLEX VIEW ON POISONING WITH NERVE AGENTS AND ORGANOPHOSPHATES
}

\author{
Jiř́ Bajgar \\ University of Defence, Faculty of Military Health Sciences, Hradec Králové, Czech Republic: Department of Toxicology
}

\begin{abstract}
Summary: OP/nerve agents are still considered as important chemicals acting on living organisms and widely used in human practice. Nerve agents are the most lethal chemical warfare agents. They are characterized according to their action as compounds influencing cholinergic nerve transmission via inhibition of AChE. The symptoms of intoxication comprise nicotinic, muscarinic and central symptoms, for some OP/nerve agents, a delayed neurotoxicity is observed. Cholinesterases ( $\mathrm{AChE}$ and $\mathrm{BuChE}$ ) are characterized as the main enzymes involved in the toxic effect of these compounds including their molecular forms. The activity of both enzymes (and molecular forms) is influenced by inhibitors and other factors such as pathological states. There are different methods for cholinesterase determination, however, the most frequent is the method based on the hydrolysis of thiocholine esters and following detection of free SH-group of the released thiocholine. The diagnosis of $\mathrm{OP} /$ nerve agents poisoning is based on anamnesis, the clinical status of the intoxicated organism and on cholinesterase determination in the blood. Some principles of prophylaxis against OP/nerve agents poisoning comprising the administration of reversible cholinesterase inhibitors such as pyridostigmine (alone or in combination with other drugs), scavengers such as preparations of cholinesterases, some therapeutic drugs and possible combinations are given. Basic principles of the treatment of nerve agents/OP poisoning are described. New drugs for the treatment are under experimental study based on new approaches to the mechanism of action.
\end{abstract}

Key words: Organophosphates; Nerve agents; Acetylcholinesterase; Symptoms; Treatment; Diagnosis; Prophylaxis

\section{Introduction}

Phosphorus plays a very important role in living organisms, e.g. in photosynthesis, metabolism, synthetic reactions, nucleic acids, coenzyme systems, transmission of signals etc. Organic phosphates are involved in energetic metabolism (ATP, phosphorylated saccharides) and influence the action of hormones or neuromediators (c-AMP, c-GMP). Chemically synthesized organic compounds of phosphorus show a broad variety of biological properties.

Organophosphorus inhibitors of cholinesterases (commonly called organophosphates, OP) are the most important chemicals in this group. They are anticholinesterase compounds. OP poisoning is commonly reported internationally $(38,60,91)$. These compounds produce acute effect, which is characterized by influencing cholinergic nerve transmission. These compounds are used in industry, in veterinary or human medicine and, last but not least, these compounds are, unfortunately, usable (and used) for military purposes as chemical warfare agents and as poisons used by terrorists. Terrorists have deployed nerve agents in attacks on unprotected civilians, and terrorists have expressed interest of them (115). A Japanese religious cult, Aum Shinrikyo, independently manufactured numerous chemical and biological agents. The first such attack with sarin occurred in Matsumoto in 1994 and Tokyo subway in 1995. Thousands of people were affected and dozens of people died $(101,103,109,142,143)$. In Matsumoto (1994), 600 people were poisoned and hospitalized, and 7 died. The attack in Tokyo subway (1995) resulted in 5500 people seeking hospital evaluation and 12 deaths $(101,104$, 110). These compounds are commercially available, and are used in agriculture which leads to professional, suicidal or accidental intoxications. The mechanism of action, diagnosis and treatment of intoxications with OP and nerve agents is a very hot topic at present. Moreover, some principles of the effects, diagnosis and therapy are very similar for OP and highly toxic nerve agents and, therefore, the principles described in this article can be applied in general for both groups - OP and nerve agents.

\section{Chemistry}

OP and nerve agents are anticholinesterase compounds. A large variety of compounds with different physical chemical and biological properties including toxicity can be 
observed in OP group. OP are liquids of different volatility, soluble or insoluble in water, organic solvents etc. and differ in their toxicity from practically non-toxic chemicals (malathion) to highly toxic agents such as VX and other nerve agents. Nerve agents are generally clear and often odourless liquids at room temperature (40). The components chemicals are available for benign chemical syntheses, and starting materials and methods for nerve agents synthesis are easily acquaired (102). The most important group having a significant biological effect include compounds of the general formula

$$
\mathrm{R}^{1}-\stackrel{\mathrm{P}^{\mathrm{P}}}{\|_{\mathrm{O}}^{\mathrm{P}}}-\mathrm{R}^{3}
$$

where $\mathrm{R}^{1-2}$ are hydrogen, alkyl (including cyclic), aryl and others, alkoxy, alkylthio and amino groups. $\mathrm{R}^{3}$ is a dissociable group, e.g. halogens, cyano, alkylthio group, rest of inorganic or organic acid.

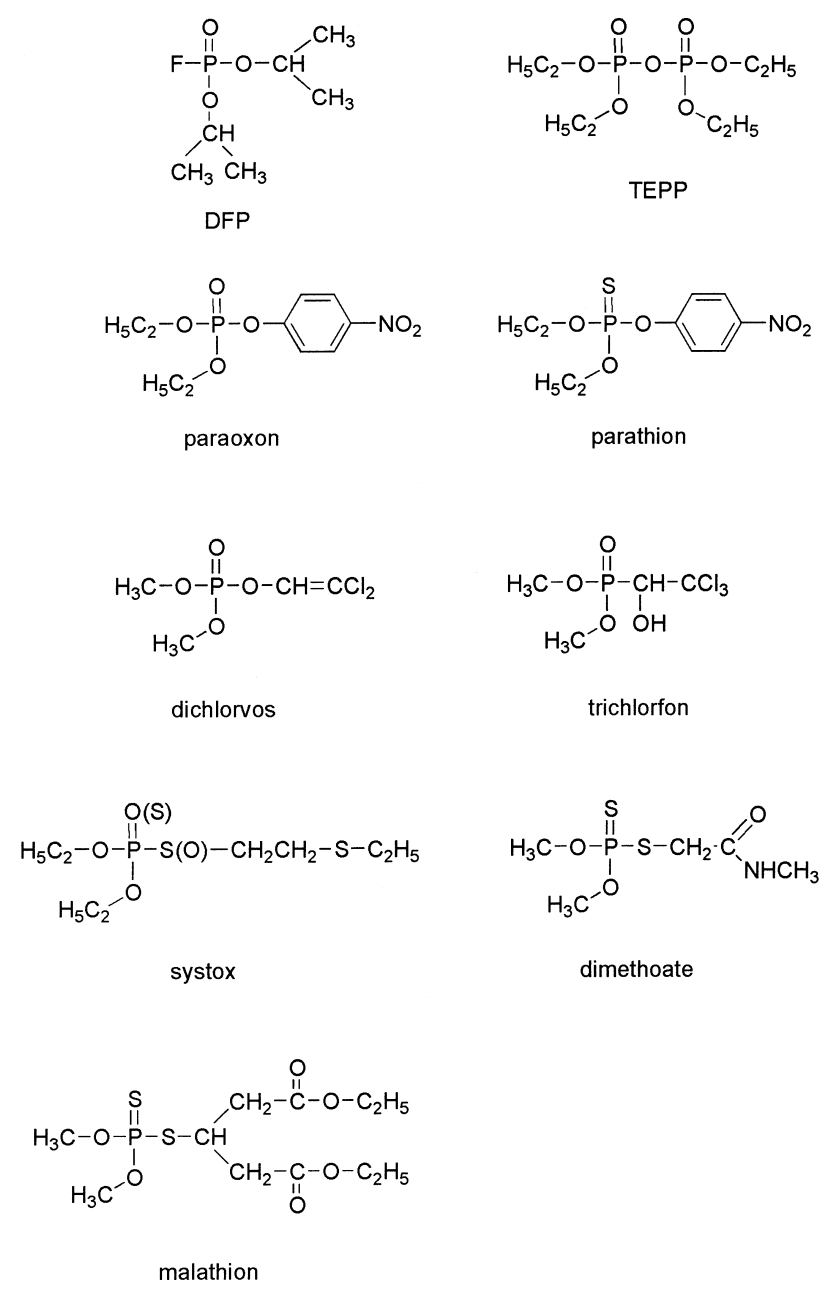

Fig. 1: Structural formulae of some OP.
Chemical formulae of some OP pesticides are shown in Fig. 1.

In the case of highly effective OP cholinesterase inhibitors (nerve agents), typical representatives are sarin, soman, tabun and cyclosarin ( $\mathrm{G}$ compounds), VX and different V-compounds (V series); and GV compounds, combining in its molecule structure of both $\mathrm{G}$ and $\mathrm{V}$ compounds. The $G$ series agents were synthesized in prewar Germany, while V series weapons (e.g. VX) were synthesized after World War II.The structural formulae of some highly toxic nerve agents are shown in Fig. 2.

\section{Mechanism of action}

The mechanism of action (toxicodynamics) of OP is based on irreversible acetylcholinesterase (AChE, EC 3.1.1.7) inhibition at the cholinergic synapses. The resulting accumulation of acetylcholine at the synaptic junctions overstimulates the cholinergic pathways and subsequently desensitizes the cholinergic receptor sites. OP/nerve agents<smiles>CC(C)OP(C)(=O)F</smiles>

Sarin<smiles>CCOP(C)(=O)N(C)C</smiles>

Tabun<smiles>CP(=O)(F)OC1CCCCC1</smiles>

Cyclosarin<smiles>CCN(CC)CCCSP(C)(=O)OCC(C)C</smiles>

SU - VX<smiles>CC(OP(C)(=O)F)C(C)(C)C</smiles>

Soman<smiles>CCOP(C)(=O)SCCNC(C)C</smiles>

$\mathrm{VX}$<smiles>CNCCOP(=O)(F)N(C)C</smiles>

GV
Fig. 2: Structural formulae of nerve agents. 
also bind to cholinesterases in the erythrocytes and serum. Although pathophysiologically less important, activities of these enzymes serve as quantifiable proxies of exposure.

However, there is a variety of documented data showing that $\mathrm{AChE}$ inhibition is not the only important biochemical change during intoxication. These data have described many other changes accompanied with the development of intoxication that might contribute to OP toxicity. They have included changes of other enzymes, neurotransmitters, immune changes, anaphylactoid reaction, behavior etc. The evidence includes the data indicating that prophylactic/therapeutic drugs might also have multiple sites of action similar to those observed during intoxication $(6,9,10,11,13$, $23,32,62,88,93,132)$. The delayed neurotoxic effect is caused by a reason other than cholinesterase inhibition. The neurotoxic esterase has been described as the target site for this symptom, however, only some OP are neurotoxic in that sense $(2,3,9,54,58,88,89)$. An interesting hypothesis was suggested by Cowan et al (32): acetylcholine acts as an agonist of autoacid release, and autoacids such as histamine can augment soman induced bronchial spasm. With respect to the demonstrable critical role of cholinergic crisis in $\mathrm{OP} /$ nerve agent toxicity, the precepts of neuroimmunology indicate that secondary adverse reactions encompassing anaphylactoid reactions may complicate OP toxicity.

The mechanism of AChE inhibition for the all OP and nerve agents is practically the same - it is its inhibition via phosphorylation or phosphonylation of the esteratic site of AChE. However, reactivation of inhibited AChE by oximes is different for different nerve agents: phosphorylated but reactivatable $\mathrm{AChE}$ is changed to a non-reactivatable complex. The half-times for this reaction described as dealkylation (42) are different for various $\mathrm{OP} /$ nerve agents $(9,10$, 42,130) (see also Chapter 6).

There have been observed many kinds of specific and non-specific effects of OP using animal experiments. They involve cholinesterase inhibition with subsequent changes of the neurotransmitters, changes in membrane permeability, and other metabolic imbalances. Markers of stress are also increased. In some OP, natriuretic affect was observed. Blood flow is decreased during $\mathrm{OP} /$ nerve agent intoxication $(6,9,32,62,88,93,132)$ (Fig. 3).

Neuropathology can be observed in animals at subconvulsive doses (2). OP compounds can directly interact with numerous neurotransmitter receptors (e.g. acetylcholinenicotinic, acetylcholine-muscarinic M2, GABA-A etc.), second messengers, and neuronal structural proteins $(29,123$, 137). Morphological changes following OP poisonings were demonstrated, too. Sližová et al. demonstrated changes in microvascularization of some rat organs (the most expressed in the liver) following soman administration in sublethal doses $(124,125)$. Morphological changes in the brain and heart were observed by Tryphonas and Clement (133) following sublethal soman intoxication beginning $30 \mathrm{~min}$ after the injection of soman and progressing 7 day. Shih et al. (122) have demonstrated that soman-induced convulsions are associated with postexposure brain pathology. These findings lead to the hypothesis that central cholinergic mechanisms are primarily involved in eliciting convulsions following exposure to highly toxic OP such as soman and the subsequent recruitment of other excitatory neurotransmitter system. Loss of inhibitory control may be responsible for sustaining these convulsions and for producing the subsequent brain damage. The important role of glutamate and its transporters has been demonstrated during soman poisoning $(62,84,135)$.

It has been described earlier that excitatory amino acids play an important role during OP poisoning. (126). On this basis, the good protective activity of adenosine receptor agonists has been demonstrated (135).

A scheme containing four basic actions (absorption, transport, metabolization and the toxic effect) was described

\section{Stressogenic $\uparrow$}

(ACTH, corticosterone, cAMP, cGMP, tyrosine aminotransferase)

water and mineral metabolism $\uparrow$

(natriuretic effect)

$$
\begin{gathered}
\text { haematological effects } \\
\text { (leucocytes } \uparrow \text {, blood flow } \downarrow \text { ) } \\
\text { liver (esterases } \downarrow, \\
\text { (transaminases } \uparrow \text {, phosphatases } \downarrow \text { ) } \\
\text { immune reactions } \downarrow \\
\text { (humoral and cellular immunity) }
\end{gathered}
$$

mutagenic $\uparrow$

( RNA $\rightarrow$ proteins)

other transmitters systems $\uparrow$

(catecholamines, GABA)

OP, NERVE AGENTS

$$
\begin{aligned}
& \text { detoxification } \\
& \text { binding } \\
& \text { excretion } \\
& \text { metabolization }
\end{aligned}
$$

lipid peroxidation $\uparrow$

AChE, BuChE $\downarrow$ acetylcholine $\uparrow$

energetic metabolism respiratory muscles, heart $\left(\mathrm{pO}_{2} \downarrow, \mathrm{CO}_{2} \uparrow\right)$

glucose, lactate, pyruvate $\uparrow$ ACIDOSIS

Fig. 3: Schematic representation of possible effects of OP/nerve agents (modified from cit. 9,10). 
previously (9). The absorption is accomplished by penetration of OP through biological barriers into the blood representing the transport system. The losses originate either physically or biologically. This part of OP (reacting by this mechanism) is screened out from toxic action. The losses in the transport system originate from detoxification and nonspecific binding to proteins and enzymes - esterases, AChE and butyrylcholinesterase (BuChE). Binding to plasma proteins is included, too. Inhibition of cholinesterases in the blood is practically the first target for OP according to the principle „first come, first served“ (24). The OP is carried out at the sites of metabolic and toxic effects. However, there are differences especially in the detoxification of highly toxic nerve agents: G-agents like sarin and soman are detoxified but compounds containing the P-S bond ( $\mathrm{V}$-agents) are not detoxified $(9,13,14)$. The toxic effect site is a multicompartmental system, minimally the central and peripheral nervous systems. In these places, OP reacts with cholinesterases - $\mathrm{AChE}$ and $\mathrm{BuChE}$. Inhibition of cholinesterases is a trigger mechanism for the toxic action of OP. Important nerve agents, soman and sarin are rapidly absorbed at all routes of administration including inhalation, percutaneous and oral administration $(9,13,14)$ and inhibit cholinesterases (preferably AChE) in the central and peripheral nervous system. Because of soman's high lipophility, it possesses a high affinity to the brain $\operatorname{AChE}(13,15)$. Sarin is less lipophilic, however, its affinity to the brain $\mathrm{AChE}$ is also very high $(9,15)$.

Both groups of nerve agents (G- and V-compounds) are potent inhibitors of cholinesterases in vitro and in vivo $(4,9,11)$. From the point of view of pharmacodynamics and therapeutic possibilities, soman represents the most serious poison. Its toxicity is comparable to that of sarin and VX $(9,15,121)$ but the therapeutic efficacy of the antidotal treatment with current and perspective drugs is not good enough $(9,13,17,63,93)$. This is probably a reason for intensive research dealing with soman intoxication and treatment.

In general, $\mathrm{G}$ compounds are detoxified in the liver, plasma (9) and, according to some authors, also in the lungs (120); and therefore this part is excluded from the toxic effect. The parent compounds can be monitored in the blood stream as well as metabolites which are excreted in urine $(9,24,105-107)$. Binding to non-specific esterases also causes losses of G-compounds in the organism and this part of soman and sarin does not have a toxic effect. It was assessed that only $1-3 \%$ of the dose administered inhibited $\mathrm{AChE}$ in the brain, i.e. $1-3 \%$ of the dose administered caused the basic toxic effect $(9,59,86,120)$. Another factor (up to now not very elucidated) influencing soman and sarin poisoning is the existence of a depot in the organism from where the nerve agent can be released and then causes a new attack of intoxication. This depot has been described for the skin, erythrocytes, muscles and lungs $(9,59$, $115)$. Bearing in mind the very low portion of the dose administered causing the basic toxic effect, it is clear that the release of a very small quantity of sarin and soman can sig- nificantly influence the survival or death of the intoxicated organism independently of the treatment. V compounds are not detoxified in the organism (14). This is probably the reason for the higher toxicity of $\mathrm{V}$ compounds in comparison with G-compounds. The effect of V-compounds (especially VX) is prolonged in comparison with sarin and soman (134). The toxicokinetics of different nerve agents including stereoisomers have also been described (24). The mechanism of action for VX is inhibition of AChE preferably in the peripheral nervous system $(9,93)$. However, inhibition of $\mathrm{AChE}$ in the brain parts was described as being selective and most marked in the pontomedullar area of the brain $(9,14)$. Detoxification of OP with lower toxicity is also important. Moreover, for some OP especially those containing the $\mathrm{P}=\mathrm{S}$ bond, oxidation giving rise to more toxic products is observed $(\mathrm{P}=\mathrm{S} \rightarrow \mathrm{P}=\mathrm{O})$. This reaction called „lethal synthesis“ is typical e.g. for malathion (oxidized to malaoxon) or parathion (oxidized to paraoxon). Oxo-derivatives (more toxic) are released into the transport system and can cause a new attack of intoxication. A similar reaction can be observed after releasing the OP from the depot, mostly from fat tissue $(9,37,40)$. In place of the toxic effect (nervous system), the reaction with enzymes is important though some other direct interactions with receptors have been described and non-specific reactions (the stressogenic effect) have been also observed. Some OP can be mutagenic or carcinogenic $(9,40)$.Depending on the target, acute, intermediate, chronic or delayed effects are manifested $(9,88,93)$.

\section{Toxicity}

Depending on the conditions of its determination, different types of toxicity are differentiated. Acute toxicity is mostly characterized by LD50 (Table 1). Acute toxicities vary greatly among different species, they are dependent on many factors (sex, age, genetic disposition, body weight, diet, hormonal factors etc.). Especially in case of nerve agents, it can be of importance. These agents should be regarded as so-called "hit and run poisons" (24) and, therefore, e.g. time of the onset of convulsions (convulsive time, CT) or death (lethal time, LT) is very valuable information (46). The route of administration is also of great importance (9).

The modelling of OP poisoning has been extensively studied. These studies investigated, among other things, the symptomatologic assessment of OP-induced lethality in mice, expressing OP poisoning through mathematical equations, or evaluating a model for carbamate and OP-induced emesis in humans $(9,53,95)$. Predicting toxicokinetic parameters in humans from the toxicokinetic data acquired from three small mammalian species was the aim of another study (8). Similarly, possible rat models for minimal brain dysfunction have been presented. Other studies correlating structure vs. activity of both OP and their antidotes have been presented (for a review, see 9). A very interesting 
Tab 1.: Toxicities for rats (experimentally determined) and human (assessed) for different OP.

\begin{tabular}{|c|c|c|c|c|}
\hline \multirow[b]{2}{*}{ COMPOUND } & \multicolumn{4}{|c|}{ TOXICITY $\left(\mathrm{LD}_{50}\right)$} \\
\hline & $\begin{array}{l}{ }^{\text {a }} \text { i. m., rat } \\
(\mu \mathrm{g} / \mathrm{kg})\end{array}$ & $\begin{array}{l}{ }^{\text {a p.o., rat }} \\
\text { (mg/kg) }\end{array}$ & $\begin{array}{l}{ }^{\text {b }} \text { o., human } \\
\text { (mg/70kg) }\end{array}$ & $\begin{array}{l}{ }^{c} \text { i. m., human } \\
(\mu \mathrm{g} / \mathrm{kg})\end{array}$ \\
\hline VX & $12-16$ & $0,08-0,09$ & 5 & $20-25$ \\
\hline sarin & 200 & $0,7-0,9$ & $8-12$ & - \\
\hline soman & 70 & $0,5-0,6$ & $7-12$ & - \\
\hline GV & 17 & 0,19 & 8 & $20-25$ \\
\hline DFP & 800 & $1-13$ & $20-80$ & $40-50$ \\
\hline TEPP & 850 & $2-15$ & $30-100$ & - \\
\hline paraoxon & $300-500$ & 3 & $30-50$ & $300-350$ \\
\hline parathion & $500-900$ & $6-7$ & $50-200$ & $2800-3000$ \\
\hline dichlorvos,DDVP & 17440 & 62 & $500-1000$ & $150-200$ \\
\hline trichlorfon & 230000 & 625 & grams & - \\
\hline systox & 3110 & $9-14$ & $20-100$ & 4000 \\
\hline dimethoate & $1000-2000$ & $215-270$ & $1-2 \mathrm{~g}$ & - \\
\hline chlorfenvinfos & 5000 & 15 & $40-100$ & - \\
\hline dicrotofos & $7-10000$ & 22 & $100-200$ & - \\
\hline diazinon & $50-80000$ & $100-150$ & $700-1200$ & - \\
\hline fosfamidon & $10-15000$ & 27,5 & $100-180$ & - \\
\hline malathion & - & $800-1200$ & grams & - \\
\hline
\end{tabular}

a experimental data from literature $(2,9,10,38,40,46,93)$

$\mathrm{b}$ assessed data from literature $(9,14,93)$

${ }^{\mathrm{c}}$ assessed data from literature (9) and Fig. 5

and perspective approach described by Maxwell et al. (95) using the multiple regression model for in vivo rate cholinesterase inhibition contained three independent variables (blood flow, carboxylesterase and cholinesterase) and this could account for $94 \%$ of the observed variation. A theoretical expression for the protection associated with stoichiometric and catalytic scavengers in a single compartment model of OP poisoning has been described $(96,129)$. In our previous paper (9), we described the scheme of the multiple effects of OP including the influence on cholinesterases and other enzymes, detoxification, the possibility of metabolization etc. These studies were elaborated with the aim of extrapolating the data from animals to humans.

However, a simple correlation of toxicity and inhibition efficacy was not linear and statistically significant. A good correlation was achieved when the toxicity data was expressed as logarithm and the inhibition efficacy as a negative decadic logarithm of the $\mathrm{I}_{50}$ value $\left(\mathrm{pI}_{50}\right)$. The value of $\mathrm{pI}_{50}$ for human brain AChE interaction with OP allows us to extrapolate the corresponding toxicity data for humans $(9,11,14)$. The equation of dependence pI50 vs log LD50 is following:

$$
\mathrm{Y}=9.87-1.26 \mathrm{x}, \mathrm{p}<0.01, \mathrm{r}_{\mathrm{xy}}=-0.9489
$$

This extrapolation is possible for the highly toxic OP where the inhibition is the most important. This correlation is closer in case that the inhibition potency is expressed as the inhibition rate in vivo and correlated with the toxicity data (16).
These results dealing with the relationship between the inhibition efficacy and the toxicity of different OP showed a good correlation between these two parameters.

\section{Symptoms of intoxication}

Dominating signs of poisoning with OP and nerve agents are caused by hyperstimulation of the cholinergic nervous system due to an elevated level of acetylcholine caused by inhibition of AChE (acute cholinergic crisis). According to type and localization, peripheral and central muscarinic and nicotinic symptoms are observed. (Table 2). Peripheral muscarinic symptoms are observed in the exocrine glands - nasal mucosa (rhinorrhea), bronchial mucosa (bronchorrhea), sweat (sweating), lacrimal and salivary glands (lacrimation, salivation). An elevated level of acetylcholine in the smooth muscles causes miosis (iris), failure of accommodation (ciliary muscle), abdominal cramps, diarrhea (gastro-intestinal tract), micturition, increased frequency of urination (bladder) and bradycardia (heart). Peripheral nicotinic symptoms due to accumulation of acetylcholine include sympathomimetic effects, pallor, tachycardia, hypertension (autonomic ganglia) and muscular weakness, fasciculations and convulsions and later paralysis (skeletal muscles including diaphragm and intercostal muscles). Central (muscarinic and nicotinic) symptoms are not very specific and include giddiness, anxiety, restlessness, headache, tremor, confusion, failure to 
Tab. 2: Main effects of OP/Nerve agents in various sites in the body.

\begin{tabular}{|c|c|c|}
\hline $\begin{array}{l}\text { Nerve agents } \\
\text { (minutes) }\end{array}$ & $\begin{array}{c}\text { CENTRAL } \\
\text { giddiness, anxiety, restlessness, headache, tremor, } \\
\text { confusion, failure to concentration, convulsions } \\
\text { respiratory depression }\end{array}$ & $\begin{array}{c}\text { OP } \\
\text { (hours) }\end{array}$ \\
\hline $\begin{array}{c}0-5 \\
5-10 \\
10-15\end{array}$ & $\begin{array}{c}\text { MUSCARINIC } \\
\text { increased secretion - rhinorrhea, salivation, } \\
\text { lacrimation, bronchorrhea, sweeting, } \\
\text { miosis, failure of accommodation, abdominal cramp, } \\
\text { diarrhea, bradycardia, hypotension, involuntary micturition }\end{array}$ & $\begin{array}{l}0-1 \\
1-3 \\
3-8\end{array}$ \\
\hline $20-60$ & $\begin{array}{c}\text { NICOTINIC } \\
\text { weakness, fasciculations, convulsions, } \\
\text { generalized convulsions }\end{array}$ & $2-8$ \\
\hline $30-60$ & $\begin{array}{c}\text { DEATH } \\
\text { failure of heart and ventilation functions }\end{array}$ & $2-24$ \\
\hline
\end{tabular}

concentrate, convulsions, respiratory depression etc. These effects are called the cholinergic effects. OP/nerve agents have got many other effects that have an influence on various organs and systems. They are called non-specific (noncholinergic) effects. These effects are usually registered later, after the manifestation of the cholinergic effects. Therefore, the $\mathrm{OP} /$ nerve agent poisoning can be divided into three phases $(9,88,93)$ : cholinergic phase characterized by cholinergic effects (also called acute cholinergic crisis), transitional phase characterized by mixed cholinergic and non-cholinergic effects and non-cholinergic phase characterized by the predominance of non-specific effects. The intermediate syndrome in OP poisoning is clinically characterized by weakness in the territory of cranial nerves, weakness of respiratory, neck and limb muscles, and depressed deep tendon reflexes. It occurs between the acute cholinergic crisis and the usual onset of OP-induced delayed neuropathy $(3,58,59)$. Postexposure changes of neurological character have also been observed (26). It was recently demonstrated that low doses of nerve agents also caused long lasting changes in behavior and neuroexcitability in experimental animals $(12,69)$. In the CNS, OP have both acute and long-term effects $(12,61,69,98,115)$ The cholinergic system has widespread distribution in the CNS, and it plays primary roles in attention, arousal, and memory (115).

The time course of poisoning is dependent on the type of agent, the dose incorporated and the route of exposure. Symptoms appeared minutes after inhalation of nerve agents and minutes to hours after incorporation of OP pesticides. Death can be observed (without treatment) within minutes after nerve agent inhalation and within hours to days after OP pesticide exposure. $(9,46,88,93$ and others). In the sarin attack in Matsumoto, the critically ill were noted to have hyperglycaemia, hypokaliaemia, and/or hypolipoidaemia. An increased level of creatine phosphokinase was noted in more than $10 \%$ of victims. Neurologically, $22 \%$ had headache, $12 \%$ had malaise, $6 \%$ had dysesthesia and some had EEG abnormalities. Low-grade fever and leucocytosis were noted in less than $10 \%(97,108)$.

Following poisoning with some OP, the delayed neurotoxic effect called also OrganoPhosphate Induced Delayed Neurotoxicity (Neuropathy) (OPIDN) can be observed. It is characterized by sensoric and motoric disturbances of the peripheral nervous system (degeneration of axons and myeline and inhibition of so called "neurotoxic esterase“). OPIDN is manifested following OP exposure (some times it is not accompanied by acute syndromology) during days (weeks) after the exposure. After a latent period (1-4 weeks), cholinergic irritation can be observed in about $30 \%$ of patients (increased salivation, nose secretion, pharyngitis, laryngitis). Paralysis of the leg muscles follows these symptoms for 1-2 weeks, persisting 1-2 months without significant changes of sensitive innervation. Then denervation and atrophy of the leg muscles is observed. Partial restitution is possible, however, convalescence is too long, abnormal reflexes are observed for years. Tri-O-cresyl phosphate (TOCP) has been reported as the typical compound producing OPIDN $(3,9,58,59)$. There has been a single case report of nerve agents exposure causing OP-induced neuropathy (57).

Sarin-exposed victims, when compared with unexposed victims at 1 and 3 years after the Matsumoto attack, had significantly different complaints. The severity of their fatigue, asthenia, shoulder stiffness, insomnia, slight fever, narrowing of the visual fieldblurred vision, and asthopenia was positively associated with the grades of exposure (104). Indications were obtained for long-term effects of low-level inhalation exposure of rats to sarin. Some changes in behavioural characteristics, such as decrease in activity and mobility, persisted for 3 to 12 months $(12,69)$. Thus, nerve agent poisoning is associated with long-term CNS changes both in experimental animals and in humans appearing especially following exposure to low concentrations of nerve agents. The data available for nerve agents (especially sarin) do not support a hypothesis on carcinogenic, mutagenic and teratogenic properties of nerve agents $(9,88,93)$. 


\section{Cholinesterases}

Cholinesterases belong to the group of hydrolases splitting the ester bond, i.e. the esterase subgroup catalyzing the hydrolysis of esters to alcohol and acid. Cholinesterases hydrolyze choline esters more rapidly than other esters and are sensitive to OP and eserine.

According to the affinity to natural substrates - choline esters - cholinesterases are divided into AChE and BuChE. AChE, specific or true cholinesterase, the "e" type of cholinesterase (EC 3.1.1.7) with a higher affinity to acetylcholine than to butyrylcholine, and splitting acetyl-beta methylcholine. It is inhibited by an excess of substrate. High AChE activity was observed in erythrocytes, the brain, the electric organ of Electrophorus Electricus and the neuromuscular junction. However, AChE activity was observed in many tissues including plants, e.g. onion (55). AChE is composed from subunits. BuChE, pseudocholinesterase, non-specific cholinesterase, the "s"-type of cholinesterase (EC 3.1.1.8) is present in the plasma (serum), pancreas and liver (where it is synthetized). It is ubiquitous enzyme present not only in some human and animal tissues but also in many plants, microorganisms etc. BuChE does not hydrolyze acetyl-beta-methylcholine and has a higher affinity to butyryl- and propionyl choline in comparison with acetylcholine. Substrate inhibition was not observed. There exist BuChE isoenzymes that are genetically determined. Depending on the genetic material, some individuals have a very low or no BuChE activity $(1,9,27,139)$.

A qualitative difference between the BuChE of suxamethonium sensitive individuals and that of other patients were demonstrated by Whittaker (139). These people with genetically diminished BuChE activity may be at higher risk when exposed to pesticides or suxamethonium $(1,87)$. The plasma of individuals with normal BuChE activity hydrolyzes succinylcholine or bind a part of OP pesticide and, therefore, the real dose of these compounds penetrating to the target sites is diminished. In case of absence of $\mathrm{BuChE}$, the dose administered is not decreased and, therefore, relative overdosage is occurred.

$\mathrm{AChE}$ and $\mathrm{BuChE}$ differ in their enzymatic properties and physiological function $(9,94,112)$. AChE splits neuromediator acetylcholine at the cholinergic synapses. It was also observed in erythrocytes but its function here is not yet known in detail similarly as the function of BuChE activity in plasma, though there is evidence that BuChE plays an important role in cholinergic neurotransmission and could be involved in other nervous system functions, in neurological diseases and in non-specific detoxification processes (112).

A more detailed knowledge of cholinesterases occurred with the description of the molecular structure of AChE (127). Like other serine hydrolases, AChE contains a catalytic triad so-called the esteratic site $\left(\mathrm{Ser}_{200}-\mathrm{His}_{440}-\mathrm{Glu}_{327}\right)$ at the bottom of a deep and narrow cavity, known as the „aromatic gorge“. In addition to the catalytic center sub- sites, AChE possesses one or more additional binding sites for acetylcholine and other quaternary ligands. Such peripheral anionic binding sites are at the lip of this gorge. In $\mathrm{BuChE}, \operatorname{Trp}_{279}$, an important component of the peripheral binding site in AChE is missing. This site is believed to be responsible for substrate inhibition, which is one of the features that distinguishes $\mathrm{AChE}$ from $\mathrm{BuChE}$. Hypothetic scheme of the active surface of AChE is given in Fig. 4.

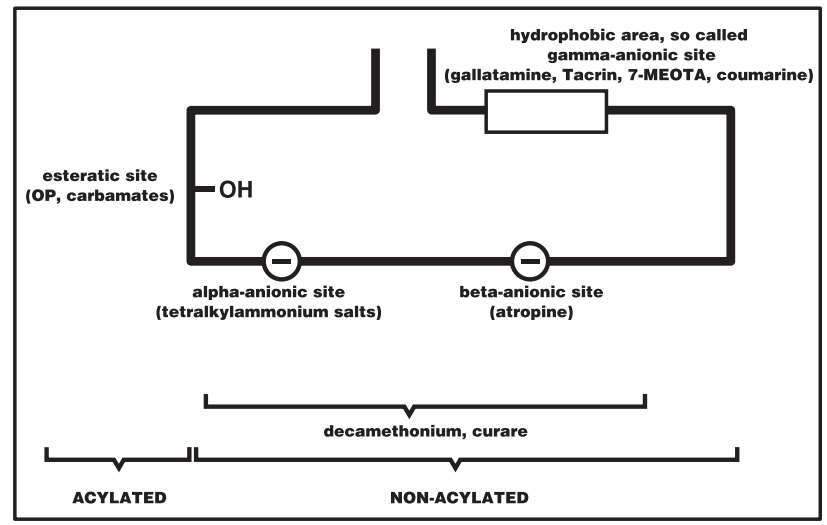

Fig. 4: Schematic structure of the active surface of AChE indicationg different binding sites for various ligands.

Determination of cholinesterase activity is based on many principles. In general, an enzyme is added to the buffered mixture and the enzymatic reaction is initiated by adding the substrate. Different parts of the reaction mixture are determined (continually or discontinually), i.e. unhydrolyzed substrate or reaction products, both directly or indirectly. The conditions must be chosen very carefully because of different factors influencing the activity.

According to the procedure and laboratory instrumentation, the most common methods of cholinesterase determination are as follows:

Electrometrical, titrimetric, manometric, colorimetric detection of the unhydrolyzed substrate, measurement by the change of $\mathrm{pH}$ using an indicator, spectrophotometric, fluorimetric, radiometric, calorimetric, polarographic, enzymatic, and others e.g. near infrared spectroscopy, These methods are also suitable for the detection of cholinesterase inhibitors using biosensors or immunochemical assay for detection of chemical warfare agents. More detailed review dealing with the methods of cholinesterase determination including literature sources was given previously $(9,11)$.

A very sensitive and commonly used method for cholinesterase determination was described by Ellman et al. (39), based on hydrolysis of the thiocholine substrates acetyland butyrylthiocholine or others. After enzymatic hydrolysis, the relevant acid and thiocholine are released and thiocholine by its SH-group is detected using 5,5'dithiobis-2 nitrobenzoic acid forming 5-mercapto-2-nitrobenzoate 
anion determined spectrophotometrically at $412 \mathrm{~nm}$. Sometimes this method is used with specific inhibitors and there are many modifications described in the literature. This method is in good correlation with other methods. It is sufficiently specific and sensitive and it is used for different purposes in many laboratories around the world. Expression of the activity varies greatly, usually as $\mu$ moles of substrate hydrolyzed per min (time) per ml of material examined (e.g. plasma, serum) or per mg of weight tissue (wet, dry, mg of nitrogen etc.). From these values, the expression of the activity in Units can be derived (it is the quantity of enzyme catalyzing $\mu \mathrm{mol}$ of substrate per min at standard conditions). In the clinical laboratory, the activity can be also expressed as catal per litre, i.e. $1 \mathrm{~mol}$ of substrate hydrolyzed per sec per litre or $\mathrm{kg}$ (cat/l, $\mathrm{kg}$ ) which is hydrolysis of $1 \mathrm{~mol}$ of substrate hydrolyzed per sec per 1 or $\mathrm{kg}$ (mol. $\mathrm{sec}^{-1} \cdot 1^{-1}$ or $\left.\mathrm{kg}^{-1}\right)$. There are many publications dealing with the review and modifications of cholinesterase determination. One of the last methodical works improving the Ellman's method (39), including a description of the methods, is a paper published by Worek et al (140).

Inhibition of enzymes can basically be divided into reversible or irreversible. OP are apparently irreversible inhibitors of cholinesterases ( $\mathrm{AChE}$ and $\mathrm{BuChE}$ ) and the reaction can be expressed by a simple scheme (Fig. 5).
The principle of this reaction is phosphorylation (phosphonylation) of the serine group on the catalytic triade (active center) of AChE. The rate of spontaneous dephosphorylation is very low and it can be omitted in most cases. However, it can be improved/increased using cholinesterase reactivators (oximes) able to reactivate $\mathrm{OP} /$ nerve agentinhibited AChE. These compounds with an ionized oxime group will break the bond between AChE and OP and restore enzyme activity (reactivation) by the nucleophilic attack on phosphorylated or phosphonylated serine at the active center of the AChE molecule and liberate the free enzyme $(9,63,80,81)$. This fact is limiting factor for the therapy with reactivators. The rest of the OP/nerve agent forms a complex with the reactivator (more toxic but less stable) hydrolyzing practically immediately and not having high importance for the course of intoxication. OP inhibits $\mathrm{AChE}$ via phosphorylation of the esteratic site. The efficacy of oxime reactivation is dependent on both oxime and the conjugated phosphonate structure (90). Simultaneously, the microenvironment of the gorge plays a significant role in determining the selectivity of the substrate and inhibitors for cholinesterases. Depending on the structure of the inhibitor, inhibited AChE is dealkylated (aged) and the complex formed is resistant to the reactivation effect $(\mathrm{EP} 1 \rightarrow \mathrm{EP} 2)$. The molecular mechanism is explained by

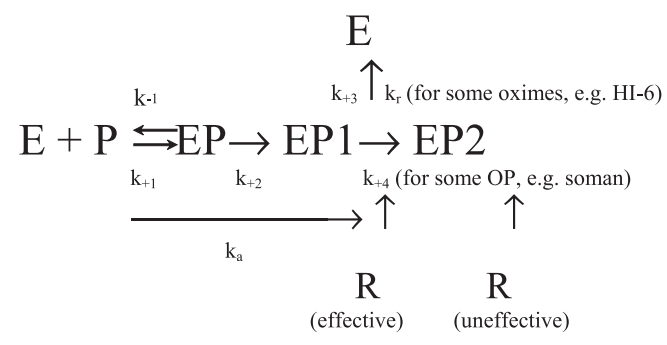

Fig. 5: Simplified representation of reaction of OP inhibitor (P) with AChE (E). The enzyme reacts with inhibitor forming intermediate complex (EP). This reaction is reversible characterized by relevant rate constants of the first order kinetics $\left(\mathrm{k}_{+1}, \mathrm{k}_{-1}\right)$. Intermediate complex is changed with relevant rate constant $\mathrm{k}_{+2}$ to phosphorylated (phosphonylated) stable enzyme (EP1). The reaction from the beginning to formation of the stable complex $(\mathrm{E}+\mathrm{P} \rightarrow \mathrm{EP} 1)$ is characterized by bimolecular rate constant $\mathrm{k}_{\mathrm{a}}$. The rate of spontaneous dephosphorylation (dephosphonylation) characterized by constant $\mathrm{k}_{+3}$ is very slow and can be omitted. However, the complex EP1 can be reversed by cholinesterase reactivators forming free enzyme (E). Therefore, the complex EP1 is reactivatable. The rate constant of reactivation $\left(\mathrm{k}_{\mathrm{r}}\right)$ is very important for the treatment. For some OP/nerve agents, the change of EP1 to EP2 is occurred. This reaction called "aging" or dealkylation leads to forming of unreactivatable complex (EP2) is characterized by $\mathrm{k}_{+4}$ rate constant. This reaction is very fast for soman-inhibited AChE. The products formed during these processes are not shown for simplicity.

\section{INHIBITED AChE (EP1) DEALKYLATED (AGED) AChE (EP2)}

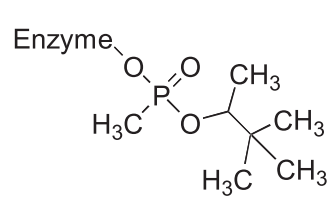



Fig. 6: Schematic representation of aging (dealkylation) of soman inhibited AChE (Enzyme). The enzyme is dealkylated and remains unreactivatable and relevant alcohol (pinacolylalcohol) is released. 
the splitting of the complex forming the alcohol and unreactivatable enzyme (Fig. 6). This reaction, called aging or dealkylation is very fast for soman-inhibited AChE (the half-life is about $10 \mathrm{~min}$ ) and it is less expressed for sarin (the half-life is about 10 hours), for VX-inhibited AChE this reaction was not observed within 24 hours $(9,40,42,130)$. This is one of the reasons for difficult therapeutic interventions of soman intoxication $(9,13,18,64,65)$. Peripheral site ligands may have selective effects on AChE phosphorylation. The importance of the orientation not only of the OP molecule but also the reactivator has been described by Luo et al. (90).

The reversibility of inhibition is very important for carbamates. They react with AChE in the same manner forming a carbamylated (inactive) enzyme preventing phosphylation of the carbamylated portion of the enzyme; however, spontaneous decarbamylation occurs very quickly and the released enzyme serves as a normal enzyme source, provided that no inhibitory concentration of an AChE inhibitor is present anymore. Therefore, reversible inhibitors (mostly carbamates) are used as prophylactics against $\mathrm{OP} /$ nerve agents intoxications $(9,18,45,66,68,70)$.

The influencing of BuChE activity by gamma-irradiation, stress, gravidity, some neurological and psychiatric disorders, hormones and medical drugs has been demonstrated $(9,11,27,33,112,139)$. The elevation of BuChE activity is not so frequent; an increase in children with nephritic syndrome has been observed $(9,139)$; an elevated ratio of $\mathrm{BuChE/LDL}$ cholesterol indicates an increase in the risk of cardiovascular diseases. The involvement of BuChE with the fat (cholesterol) metabolism has been suggested (9). The relationship between BuChE activity and experimentally induced diabetes mellitus in rats was also mentioned (for a review, see also 9,11,112).

Determination of AChE activity is not so widely used in clinical laboratories. A decrease in red blood cell AChE activity in pernicious anaemia has been demonstrated; diminished erythrocyte AChE activity is typical for paroxysmal nocturnal haemoglobinaemia and $\mathrm{ABO}$ incompatibility $(9,11)$. AChE activity in the erythrocyte membrane can be considered as an indicator of erythrocyte membrane integrity. Increased AChE activity in rectal biopsy is of great diagnostic significance in Hirschsprung's disease, especially in the presence of its atypical molecular form $(9,19)$. There are other papers demonstrating increased AChE activity in the amniotic fluid during pathologic development of the neural tube (25). AChE activity in the erythrocytes and cerebrospinal fluid is also diminished in some endogenous depressions and other psychiatric disorders; however, the results presented are not quite clear at present (for a review see, e.g. 9,11,112).

On the other hand, influencing of the cholinergic nervous system is one of the most important pathological changes in Alzheimer's disease. A lack of the cholinergic mediator, acetylcholine, was observed. This has led to attempts to correct cholinergic deficiency at various levels of cholinergic functioning: inhibitors of cholinesterases like physostigmine were used; however, physostigmine was not found to be an ideal drug for clinical use because of its short half-life, side effects etc. (44). Clinical study results showed perspective results with the acridine inhibitor of cholinesterase - Tacrin (1,2,3,4-tetrahydro-9-aminoacridine); its 7-methoxyderivative (7-MEOTA) was described as a compound of low toxicity and with good therapeutic effect in experimental intoxication with anticholinergics $(44,112)$. Biochemical studies dealing with its effect on cholinesterases in vivo showed that 7-MEOTA inhibited BuChE in the liver and $\mathrm{AChE}$ in brain parts with the highest sensitivity in the frontal cortex $(9,11,44,112)$

Metal cations are an interesting group of compounds modifying cholinesterase activity. Their effect was studied on relatively simple cholinesterase models. It was demonstrated previously that $\mathrm{Hg}$ ions especially diminish $\mathrm{AChE}$ activity in low concentrations (14).

There are other drugs influencing AChE activity, however, without basic knowledge on their mechanism of action. It was demonstrated recently that cyclosporine A diminished AChE activity in selected parts of the rat brain after administration in vivo (56). Similar studies were demonstrated with Daunorubicin in rabbits: cholinesterases in different parts of the heart were decreased in animals treated with this drug (47-50).

The factors influencing cholinesterases are not limited to chemicals only. AChE activity is connected with cholinergic activity in the brain. Using determination of $\mathrm{AChE}$, combined with defined lesions of the different parts of the brain, it was possible to demonstrate cholinergic projections in the central nervous system $(9,14)$.

AChE shows a polymorphism of quaternary structures, of similar catalytic activity but differing in their properties. Catalytic subunits, which may vary in glycosylation can oligomerise into dimers or tetramers, giving rise to the globular (G) forms: G1, G2 and G4. These forms can further be divided depending on their amphiphilicity. Attachment of a collagen-like tail to one, two or three catalytic tetramers gives the A4, A8 and A12 assymetric forms, which bind to basal lamina. Tetramers are formed by electrostatic and hydrophobic interaction between two disulphide-bonded dimers $(9,94,112)$.

Multiple molecular forms (AChE and $\mathrm{BuChE}$ ) are also influenced by many factors $(9,11)$. The function of these forms is not known at present. There are only scarce data describing the changes of AChE molecular forms following intoxication with highly toxic OP (15). Some experiments were performed with relatively less toxic OP (21). From the group of highly toxic OP compounds, sarin, soman, and VX were found to be the most effective (15).

Molecular forms of AChE showed different sensitivity to inhibitors in vitro and in vivo $(9,11,15,112)$. Intoxication with Paraoxon (less toxic OP) caused medium inhibition of some forms of AChE (21). Using thermal denaturation, it was demonstrated that they are not artifacts formed during 
homogenization or other treatment of the brain tissue (14). The overall data show that the catalytic activity of AChE molecular forms is different and that their inhibition by various inhibitors may be heterogeneous. This heterogenicity was demonstrated for AChE phosphorylating inhibitors as well as for inhibitors with different binding sites for the enzyme.

\section{Diagnosis}

A chemical exposure should enter the differential diagnosis in all mass casualty events manifesting with respiratory and neurologic symptoms. Carbon monoxide, hydrogen sulfide, certain metal exposures, and xylene can cause an acute convulsions. Only two classes of chemical warfare agents can cause the acute onset of respiratory symptoms and neurologic dysfunction: nerve agents and cyanides. Cyanide victims present without miosis and usually without cyanosis. Although seizures may be present, neuromuscular symptoms are absent $(9,115)$. The effect of $\mathrm{OP} /$ nerve agents is characterized by their interference with cholinergic nerve transmission via inhibition of $\mathrm{AChE}$ and $\mathrm{BuChE}$. The cholinergic crisis (accumulation of neuromediator acetylcholine) is accompanied by other changes disturbed membrane permeability, the stressogenic effect, inhibition of enzymes other than cholinesterases, changes in the cyclic nucleotide levels, oxygen saturation etc. There are also morphologic and immunologic changes observed soon after the intoxication. Diagnosis of OP poisoning is based on clinical signs and cholinesterase determination using the most suitable material for laboratory diagnostics - the blood. However, there are other changes in the biochemical parameters during the intoxication/exposure to OP depending on the type of such compound (mutagenicity, delayed neurotoxicity etc.).

Cholinesterase activity is fundamentally important for the diagnosis of intoxication with cholinesterase inhibitors, including OP and carbamates $(9,93,88)$. On the other hand, the activity depends on many other factors and, therefore, cholinesterase determination is of diagnostic importance in different pathological states, i.e. not only intoxications (9, 11,92). The activity of these enzymes (AChE and BuChE) is influenced by sex, age, nutrition, hormonal factors, irradiation etc. $(11,27,139)$. The variation of $\mathrm{BuChE}$ activity is greater than that of $\mathrm{AChE}(11,139)$ and it is genetically determined (139). There is a wide variation in the population for AChE erythrocyte levels by ethnic groups, age, and reproductive status. Red blood cell AChE levels are lower in infants than adults (33). In pregnancy, erythrocyte AChE activity can be elevated and serum BuChE levels can be reduced compared with non pregnant controls. Measurements of both cholinesterases is still useful for conforming the diagnosis, for monitoring recovery, or for forensic study $(9,115)$.

Clinical monitoring of intoxication and determination of cholinesterases in the blood are basic methods for the diagnosis and differential diagnosis of the intoxication with $\mathrm{OP} /$ nerve agents $(9,23,115)$. It is necessary to examine the whole picture of intoxication, i.e. not only biochemical examinations but clinical signs allowing more precise assessment the prognosis of the intoxication. As for clinical biochemistry, it is necessary to have biological samples, mostly blood and urine. The OP/nerve agent in the urine can be detected, however, their degradation is fast and therefore the time where detection in the urine is possible short. The detection of metabolites is also possible but limited for such OP metabolizing to the specific products e.g. para-nitrophenol in the paraoxon poisoning (107). For the diagnosis, the direct determinations of the toxic agent (OP or nerve agent) in the circulating system is also possible. However, the parent compound will circulate intact for a short period of time and detection will not be possible for more than approximately hours after exposure. Metabolites circulate for a longer time period and are mostly excreted in urine. A metabolite of sarin (O-isopropyl methylphosphonic acid) could be traced in urine and and plasma from victims after the Tokyo subway sarin terroristic attack (105,106). For some OP pesticides (parathion, paraoxon), detection of $\mathrm{p}$-nitrophenol in urine is an indicator of exposure (9). However, the retrospectivity of these methods is limited. The detection using an immunoassay of nerve agents is now in progress. The antibodies against soman may have the appropriate specificity and affinity for immunodiagnosis of soman exposure (85).

Therefore, the blood remains to be the main source of biological material for biochemical examination.

For occupational medicine purposes, the determination of cholinesterases in the blood of workers with OP is obligatory. A decrease of the activity below $70 \%$ of normal values is an indicator that the worker should not come into contact OP. However, the normal values varied within the laboratories depending on the method of determination. For practical purposes (individual and interindividual variation), determination of individual normal activity was recommended (this approach is more better than that of calculating the decrease from an average value) as well as separate determination of both cholinesterases, the red blood cell AChE and plasma BuChE. The erythrocyte AChE activity seems to be more useful for diagnostic purposes than BuChE activity in the plasma. In clinical biochemistry, BuChE determination in the plasma or serum is more frequently used than that of $\mathrm{AChE}$ in the red blood cells.

There are many other factors influencing BuChE activity and the diagnostic importance of diminished BuChE activity is important for the following states - except hereditary decrease of the activity and poisoning with $\mathrm{OP} /$ nerve agents and carbamates - congenital deficiency, liver damage, acute infection, chronic malnutrition, metastasis (especially liver), myocardial infarction, dermatomyositis, intoxication with carbon disulphide or mercury and obstructive jaundice $(7,9,20,23,60,92)$.

There are other biological materials available for special purposes (not for the diagnosis of OP poisoning) - amniotic fluid, cerebrospinal fluid, and bioptic materials. From 
these samples, tissue obtained by the rectal biopsy is used most frequently (diagnosis of Hirschsprung's disease). An elevated AChE activity in the rectal tissue/homogenate (detected histochemically/biochemically) is one of the good diagnostic markers indicating a need for surgical treatment of Hirschsprung disease and a criterion for diagnosis and management of obstipation $(11,74)$. The presence of an unusual AChE band after the electrophoretic separation supports the diagnosis (11,19). The same (either AChE elevation or the presence of a new electrophoretic AChE form) in the amniotic fluid can be applied for the diagnosis of malformation of the neural tube development during pregnancy (25). AChE activity in the cerebrospinal fluid is also changed in some pathological states, however, the diagnostic validity is not so high and can be considered as a complementary examination $(9,11,76,113)$.

Recently, a method was developed which is based on reactivation of phosphylated cholinesterase and carboxylesterase $(\mathrm{CaE})$ by fluoride ions (114). Based on this method for retrospective detection of exposure to OP, the exposure of victims of the Tokyo incident to an OP, probably sarin, could be established from analysis of their blood samples (41,114). A novel and general procedure for diagnosis of exposure to OP, which surpasses the limitations of the fluoride reactivation method was described (136). It is based on the rapid isolation of $\mathrm{BuChE}$ from the plasma by the affinity chromatography, digestion with pepsin followed by liquid chromatography with the mass spectrometric analysis of phosphylated nonapeptides resulting after the digestion of inhibited BuChE with pepsin. The method can be applied for the detection of exposures to various OP pesticides and nerve agents including soman (105-107). The development of the new specific methods mentioned (fluoride reactivation, tandem MS analysis of enzymatic digests of $\mathrm{BuChE}$ ) are of high importance for more precise diagnosis of $\mathrm{OP} /$ nerve agents poisoning. An extensive review of Noort et al. (105) dealing with biomonitoring of exposure to chemical warfare agents (not only nerve agents) can be strongly recommended.

As was mentioned previously, a decrease in cholinesterase activity is the factor indicating (after the exclusion of other factors) an exposure to $\mathrm{OP} /$ nerve agents or other cholinesterase inhibitors. This simple determination does not allow us to make some decisions dealing with the antidotal therapy (especially the repeated administration of reactivators) and then have low prognostic validity. Therefore a new test of the reactivation has been described (14). The principle of the reactivation test is double determination of the enzyme, the first without and the second one with the presence of a reactivator in the sample. The choice of rectivator is dependent on the availability of the oxime, however, in principle it is necessary to have in these parallel samples the same concentrations of the reagents. Using this method, in vitro reactivation of the whole human blood in vitro inhibited by various nerve agents (VX, sarin, soman) was determined. This reactivation test was used for deter- mination of the reactivatability in rats and dogs intoxicated with the same nerve agents (sarin, soman, GV and VX) (10). From these results, differential diagnosis can be derived - in the case of low reactivation (0-10\%), soman as the toxic agent is the most probable. A middle reactivation of about $50 \%$ indicates sarin intoxication and a high reactivation is typical for VX $(9,10,14)$. The delayed neurotoxic effect can be monitored by the determination of neurotoxic esterase. The determination of this enzyme in the lymphocytes soon after injection of neurotoxicants (15-30 min) permits an assessment the progress of delayed neurotoxicity (72). In vitro techniques for the assessment of neurotoxicity have been elaborated, too $(9,58)$.

An interesting and new approach was described by Gopalakrishnakone (52). The human brain cell lines were exposed to various concentrations of soman for a period of one and two day. A total of 115 and 224 genes involved in signal transduction, metabolism, cell growth, development, apoptosis and immune response were either up- or down-regulated, respectively. This approach needs to be elaborated in more detail.

Determination of $\mathrm{AChE}$ or BuChE molecular forms can be interesting and useful for improvement of the diagnosis of OP poisoning. It was demonstrated that these forms are inhibited in different manners - some of the forms are resistant (a low molecular weight), some of them are very sensitive (a high molecular weight). When the total $\mathrm{AChE}$ activity is determined, the value obtained is a „mean“ of the activities of these forms (15). From practical point of view in the clinical laboratory, it is necessary to monitor basic physiological functions, cholinesterases and other biochemical parameters not only for diagnostic purposes but also preferably for the regulation of treatment.

\section{Prophylaxis}

The decontamination can be considered as a prophylactic measure, however, it is not medical protection (prophylaxis).The prophylaxis will be focused on protection of AChE against the inhibition using reversible cholinesterase inhibitors. The diminishing the level of OP using enzymes hydrolyzing these agents or enzymes binding the agents (to specific proteins or to antibodies) and thus reducing the OP level (and inhibition of cholinesterases) in the organism can be described as detoxification. Another approach to prophylaxis is based on using present antidotes. It can be characterized as a treatment "in advance". The problem with this approach is how to achieve sufficient levels of antidotes for a relatively long time. Combinations of these approaches are also possible. Unlike other OP, the treatment of soman poisoning is very difficult and unsatisfactory. This is the reason for intensive studies using pre-treatment/prophylaxis allowing survival and increasing the resistance of the organism exposed to soman and tabun.

Keeping AChE intact is a basic requirement for effective prophylaxis, i.e. to change the enzyme in a way that will 
make it resistant to OP. This can be achieved by using reversible inhibitors, which are able to inhibit AChE reversibly and after spontaneous recovery of the activity, normal $\mathrm{AChE}$ serves as a source of the active enzyme. Moreover, $\mathrm{AChE}$ inhibited by carbamates is resistant to $\mathrm{OP} /$ nerve agent inhibition $(9,18)$.

The ability of some carbamates to protect an organism poisoned with OP has been known for many years. Physostigmine and neostigmine have been used to protect animals against DFP. The number of OP studied for protection was enlarged, as well as the number of carbamates studied. These studies were performed both in vitro and in vivo. The results are very dependent on experimental conditions; nevertheless, the protective effect of physostigmine, aminostigmine, pyridostigmine and others against $\mathrm{AChE}$ inhibition caused by different OP (mostly soman) has been demonstrated $(9,46,93,121,131)$. There have been numerous studies demonstrating the effectiveness of carbamate pre-treatment/prophylaxis against intoxication with OP. From the results published (and unpublished) it appeared that pyridostigmine was the most promising prophylactic drug especially against soman poisoning $(9,17,18,64-70,93)$. On the basis of these results, pyridostigmine was introduced into some armies as a prophylactic against nerve agents. Its prophylactic effect (like the effects of other carbamates) is limited by its dose. With a higher dose, a higher efficacy was observed, but the side effects were more expressed, too. This problem can be solved by the adding of pyridostigmine antagonizing drugs - anticholinergics. Many anticholinergics have been tested to protect the organism against intoxication with soman (and other nerve agents) and, on the basis of this research, the prophylactic combination of pyridostigmine with trihexyphenidyle and benactyzine ( 9 , $17,18,45,68,70)$ was introduced into the Czech Army as PANPAL. The presence of these two anticholinergics allowed us to increase the pyridostigmine dose and to increase its prophylactic efficacy. This combination (including followup therapy) is not limited to soman, sarin and VX poisoning but its high efficacy against tabun, GV and cyclosarin intoxications was observed $(9,18)$. The prophylactic antidote combination called PANPAL has no side effects as it has been demonstrated on volunteers: no statistically different changes in the actual psychic state as well as no negative changes in the dysfunction time were observed (45).

Other carbamates also have a good prophylactic efficacy, especially physostigmine (due to its central effect on the contrary to pyridostigmine). Human study with transdermal physostigmine suggests a serious interest in the prophylactic use of this drug $(9,73,99)$. Mobam and decarboxyfuran were also experimentally considered as potential candidates for prophylaxis. Among other inhibitors, aminophenols and OP were tested but their effects were lower in comparison with pyridostigmine $(18,93)$.

Structurally different inhibitors from the carbamate and OP groups were also studied. From these compounds (preferably binding to the AChE anionic site), tacrine, 7-MEO-
TA and huperzine A were considered and experimentally studied with respect to prophylaxis in vitro and in vivo $(9,43,83,111)$. The most interesting results were obtained with huperzine A. It is an inhibitor of the rat brain AChE $(83,111)$. Very similar results were obtained with enzymes from other sources. Huperzine A was tested as a potential candidate against OP for its long-lasting efficacy and relatively low toxicity. However, the results obtained do not support replacement of pyridostigmine by these drugs (for a review, see 18 ).

Detoxification principle can be used in two different ways: administration of enzymes splitting the OP or specific enzymes which bind the OP (cholinesterases). OP is bound to the exogenously administered enzyme and thus the OP level in the organism is decreased (it acts as "scavenger"). Enzymes hydrolysing OP are under research (30). On the other hand, many studies have been made with cholinesterases as scavengers. BuChE and $\mathrm{AChE}$ were observed to be very effective in protection against OP intoxication $(18,31$, $34,35,100,117,118)$. The administration of enzymes as scavengers seems to be very promising: the enzyme is acting at the very beginning of the toxic action, without interaction with the target tissues and without side effects $(34,35,117)$. All of these features are of great interest and they are yielding practical results - isolation of the enzyme, examination for lack of and auto immune response, stability, and establishment of pharmacokinetic and pharmacodynamic properties (117). Moreover, BuChE pretreatment also showed protective effects on AChE inhibition in the brain parts following low level sarin inhalation exposure (118). Given our increasing knowledge in bioengineering and biotechnology, the connection between these two enzymes will be possible with the aim of obtaining a modified enzyme splitting OP and simultaneously reacting with $\mathrm{AChE}$ as a scavenger (30). Antibodies against OP are in the stage of research and they are more focused on the detection of OP (85).

The idea on use of standard antidotes as prophylactics is very simple - to achieve sufficient level of antidotes in the blood vessel before intoxication. Standard antidotes were studied in this respect i.e. anticholinergics, reactivators, anticonvulsants and others $(18,28,77,93,97)$. The problem with their use is the timing and duration and achievement of sufficient levels of these antidotes after administration. However, the prophylactic efficacy is good as it has been demonstrated in treatment studies - administration of the antidotes mostly takes place very shortly (minutes) after the intoxication. The prolongation of the duration of the antidote effects by achievement of their sufficient level in the blood by oral administration is not possible (especially reactivators) and therefore it is excluded. It was a reason for searching for other routes of administration. Transdermal administration of one of the most effective reactivators (HI-6) was shown to be the most realistic approach $(9,18$, 36). The final result was the new prophylactic transdermal antidote TRANSANT containing the reactivator HI-6. This preparation was clinically tested (including dermal sensiti- 


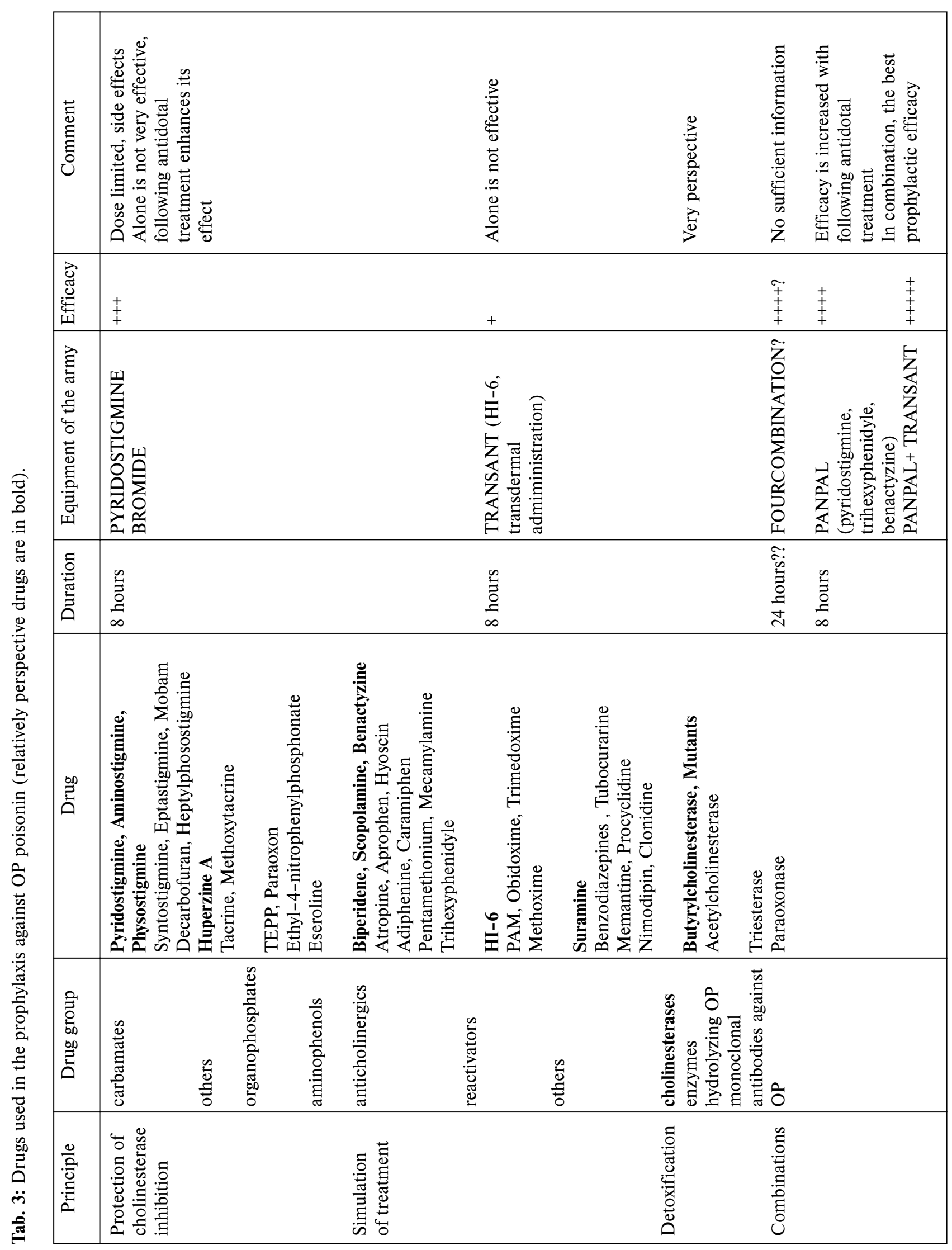


vity) without any harmful effects and field testing was also successful and TRANSANT was introduced into the Czech Army. The prophylactic efficacy of other drugs was studied. As anticonvulsant drugs, benzodiazepines (diazepam, midazolam, alprazolam, triazolam, clonazepam) were studied, but isolated prophylactic administration has not had very good effects $(4,9,18,93)$.

There are other drugs tested as prophylactics. Calcium antagonists (nimodipine), neuromuscular blockers (tubocurarine), adamantanes (memantine), and the opiate antagonist meptazinol were also tested with different results but they were not very useful for practical use (18). On the other hand, a positive prophylactic effect has been demonstrated with procyclidine (antimuscarinic, antinicoticnic and the anti-NMDA receptor drug) $(9,18)$. Special importance can be focused on suramine (a protease inhibitor). Administration of this compound prior to soman intoxication (and followed by administration of atropine) showed good prophylactic effect $(18,32)$. However, all these studies are experimental ones and they have not reached the practical output stage. The combinations of various drugs as prophylactics can be of very different character. They can be used simultaneously (a combination of different drugs) or as pre-treatment and following treatment with different antidotes. Administration of pyridostigmine (or other inhibitors) prior to intoxication and treatment with different drugs is a typical example $(4,9,17,18,45,66-68)$. There are other combinations such as the administration of triesterase, procyclidine, clonidine, sustained release of physostigmine and scopolamine $(9,18,73,99)$. The results are very dependent on experimental conditions but this approach administration of different drugs - has yielded some good results though up to now they have been on an experimental level. Only three prophylactics have been introduced into the armies - PANPAL composed of pyridostigmine, benactyzine and trihexyphenidyle, TRANSANT (HI-6) and pyridostigmine bromide, respectively. There are some indications on fourcombination introduced in one east army but without further specification cannot be considered as serious (Table 3 ).

It appears from these results that simple prophylaxis (without postexposure treatment) against $\mathrm{OP} /$ nerve agents is not sufficient enough. Therefore, pyridostigmine has importance as a prophylactic drug especially when it is connected with postexposure antidotal treatment. For further development, it is necessary to search for new prophylactic drugs and new routes of administration. In this connection, preparations of cholinesterases are of special importance for the development of more effective prophylactics.

\section{Treatment}

The general priorities after $\mathrm{OP} /$ nerve agent intoxication are: evacuate the toxic zone, decontaminate, resuscitate victims while initiating antidotal treatment, and secure definitive treatment. The pillars of complex therapy for any nerve
agent/OP casualties include: intensive respiratory care, antidotal therapy, treatment of complications and monitoring, and care for long-term sequelae. Based on our knowledge of the mechanism of action, two therapeutic principles for antidotal treatment are used. The main drugs are anticholinergics that antagonize the effects of accumulated acetylcholine at the cholinergic synapses (also called symptomatic antidotes) and cholinesterase reactivators (oximes) to reactivate inhibited AChE (causal antidotes). Their effects are synergistic. Central nervous antidepressants such as benzodiazepines are also used to treat convulsions (anticonvulsants). Due to the high toxicity of $\mathrm{OP} /$ nerve agents, first aid is important for the future fate of the intoxicated organism. It consists of interrupting contacts with the poison (evacuation, protective mask), administration of antidotes if possible, and decontamination. Support of vital functions (the heart, artificial respiration) is necessary. Though administration of the above-mentioned antidotes is recommended, successful therapy of moderate $\mathrm{OP} /$ nerve agent and carbamate poisoning has been described using atropinization and the treatment of acidosis with natrium bicarbonate only $(22,109)$.

Atropine is the anticholinergic drug most frequently used for the treatment of human poisoning. This muscarinic cholinergic antagonist acts by blocking the overstimulating effects of acetylcholine at the muscarinic sites and has little effect at the nicotinic sites. It does not readily cross the blood-brain barrier but it has central ameliorative effects. Atropine reverses central apnea, relieves bronchoconstriction, and dries secretion, i.e. it reverses the peripheral muscarinic symptoms (e.g. secretion etc.) and arrests the early phase of convulsions when given within minutes of exposure (98). Atropine will not improve neuromuscular function, particularly diaphragmatic function. Ketamine (an antagonist of glutamatergic NMDA receptor and bronchodilatator) should be used with the caution in nerve agent poisoning. In animal experiments, central apnea quickly ensued when NMDA receptor antagonists were administered before atropine (18). Atropine pre-treatment prevented this effect $(9,18)$. In experiments on animals, the good therapeutic efficacy of benactyzine and biperidene was observed especially against soman poisoning due to its better central effect in comparison with atropine (66). Though some doubts exist about administration of very high doses of atropine, the treatment of human casualties and experimental intoxications are clear $(18,38,71,96,115)$ : in severe poisoning both the animal and human data show that very high doses of atropine are life saving and well tolerated. Animals exposed to $2 x L D 50$ soman were capable of tolerating $0.5-3.0 \mathrm{mg} / \mathrm{kg}$, i.v. atropine: this equates to $35-210 \mathrm{mg}$ in a $70 \mathrm{~kg}$ human. These doses agree with Iranian casualty data. Animal studies show lower doses of atropine (0.1-0.2 $\mathrm{mg} / \mathrm{kg}$ ). Therefore higher doses of diazepam or more efficient anticonvulsant are required. Lower atropine doses increase the risk of lethality from poor cardiorespiratory response and long period of unconsciousness and possibly 
seizure activity, and, therefore, increase the potential for neurological damage. The further course of OP intoxication is negatively influenced by a low dosage of atropine $(9,23$, 115). High doses of atropine return consciousness more rapidly and support cardiorespiratory efforts. Aggressive atropinization and prolonged administration of the oxime improved the fate of OP-intoxicated patients $(9,23,115)$. Other anticholinergics may be even more efficacious. The centrally acting anticholinergics (benactyzine, biperidene) can be very useful in the therapy and reduce the necessary amounts of benzodiazepine anticonvulsants $(9,51,75)$. Nerve agents have a long-term effect on the behavior of experimental animals lasting months after intoxication with low doses of nerve agents and were eliminated with pharmacological pretreatment followed by antidotal treatment $(9,12,69,77)$. However, adding diazepam into the therapeutic mixture improved the survival of tabun-intoxicated mice when combined with atropine and methoxime (119). The anticonvulsant action of some anticholinergics in soman poisoning was demonstrated (28).

The current standard treatment with reactivators includes different types of oximes with a similar basic structure differing by the number of pyridinium rings and by the position of the oxime group in the pyridinium ring. Oximes hydrolytically cleave the OP/nerve agent from AChE, restoring enzymatic function. From the common oximes, monoand bisquaternary pyridinium oximes are frequently used such as pralidoxime, obidoxime, trimedoxime, methoxime and HI-6 (Fig. 7). Because of some doubts about the use of oximes in the treatment of OP poisoning, Eddleston et al. (38) published a systematic review of clinical trials dealing with oxime therapy in acute OP poisoning. His generalized statement that pralidoxime should not be used in OP poisoning was not supported by the published results. The use of the reactivators is supported by the observations of OPpoisoning $(9,37,128,138,141)$.

The effectiveness of antidotal treatment is dependent on the reactivatability of $\mathrm{AChE}$ by the reactivator used $(9,23,63)$. Generally, the conventional oximes (pralidoxime or obidoxime) have been considered to be sufficiently effective against VX, sarin and cyclosarin, and rather ineffective against soman $(9,63,75)$.

The differences in the oxime efficacy against various nerve agents are mainly due to the various aging rates at which inhibited $\mathrm{AChE}$ is converted to a form that can no longer be reactivated by oximes $(9,40,42,63)$. The reactivation of VX, sarin, or GF-inhibited AChE is still possible hours after the intoxication while soman-inhibited AChE becomes unreactivatable within minutes and, therefore, renders the treatment of soman poisoning much more difficult $(9,10,63)$.

This fact led to the synthesis of a series of bisquaternary oximes, designated as „H-oximes“, that in combination with anticholinergic drugs have been relatively successful in antagonizing soman intoxication $(9,63,121,122)$. Among the H-series oximes, HI-6 has been the best studied and, there-<smiles></smiles>

Pralidoxime<smiles>CC[n+]1ccc(/C=N/O)cc1</smiles>

Trimedoxime<smiles>C[n+]1ccc(/C=N/O)cc1</smiles>

Obidoxime<smiles>C[n+]1ccc(C=NO)cc1C=NO</smiles>

Hlö-7

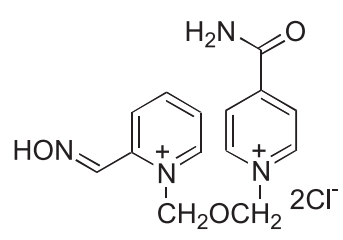

HI-6<smiles>CN1C(C=N)=CC=C[C-]1C=C=O</smiles>

BI-6<smiles>O=Cc1cc[n+](C[n+]2ccc(C=NO)cc2)cc1</smiles>

Methoxime<smiles>C[n+]1ccc(C=NO)cc1</smiles>

K048<smiles>C[n+]1ccccc1C=NO</smiles>

K033

Fig. 7: Structural formulae of some reactivators. 
fore, seems to be the most promising oxime against soman poisoning (9,63). Worek et al. (141), based on experimental testing of the reactivation potency of obidoxime, pralidoxime, HI-6 and HLő-7 in human erythrocyte AChE inhibited by nerve agents, suggested that HLö 7 may serve as a reactivator in nerve agent poisoning at doses therapeutically relevant in humans.

If we compare the AChE reactivatability of different oximes and various nerve agents, i.e. the dependence of the percentage of rectivation vs. concentration of the oxime $(9,63)$, basically two different types of the curves can be obtained: the first depending on the oxime concentration shows an increase with a maximum followed by a decreased part of the curve. The second type is a sigmoid curve reaching to the maximum but the decrease cannot be demonstrated because of a too high concentration of the oxime (very probably it will be the same, i.e. containing a decreasing part). Obidoxime and pralidoxime are effective against cyclosarin-and sarin-inhibited $\mathrm{AChE}$ at concentrations reaching to $10^{-3}-10^{-2} \mathrm{M}$ (Fig. 8). Therefore the effectivity of the oxime in a human can be influenced by the concentration in the target organs, i.e. when administered parenterally, in the dose range of $470-2280 \mu \mathrm{mol} / \mathrm{kg}$, the concentration in the brain can be about $10^{-4}-10^{-5} \mathrm{M}(9,63)$. These concentrations are able to reactivate sufficiently inhibited AChE in

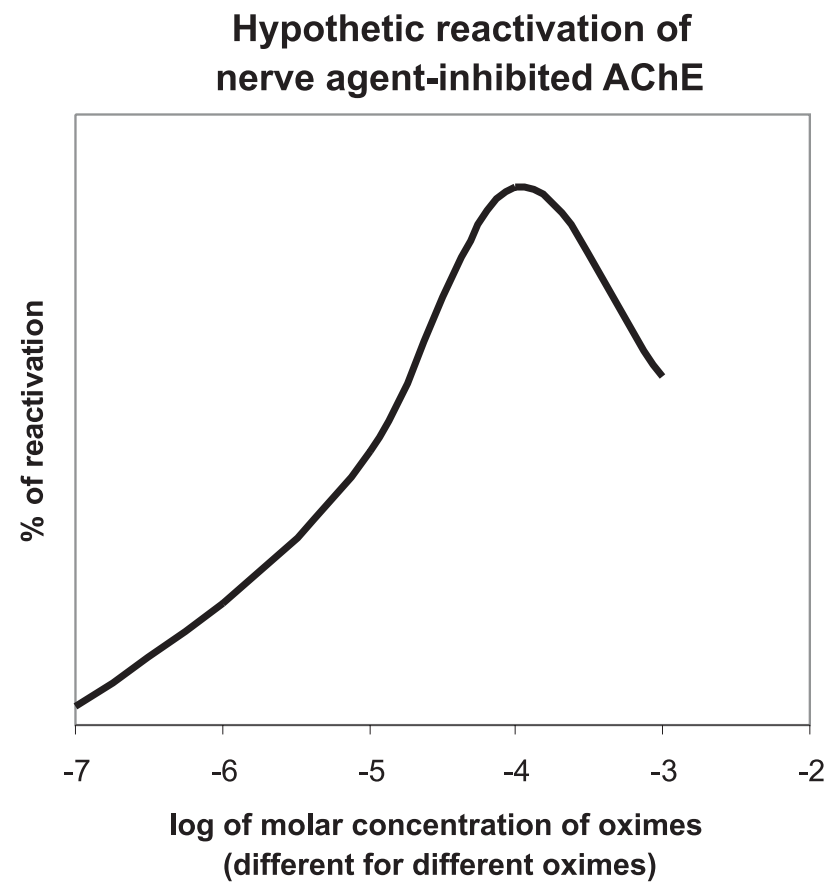

Fig. 8: Hypothetic reactivation of AChE inhibited by nerve agents.In this case, concentration $10^{-4} \mathrm{M}$ is the maximum available in human, concentration $10^{-6}$ (in this case) is the minimum necessary for "life saving" AChE reactivation (10-20\% reactivation). However, different reactivators differ in these concentrations and this is limiting factor for antidotal therapy. the brain especially in the ponto-medullar area (the increase by $10-20 \%)$ : the minimal level of AChE activity in the pontomedullar area necessary for the survival of nerve agentsintoxicated animals was assessed to be about $5 \%(9,14)$.

The crucial question dealing with the reactivator's effect on the central nervous system was discussed in the past. Because of their quaternary structure, at intact BBB, the penetration of the reactivators is slow. In order to reach an effective concentration of the reactivator in CNS, its extremely high plasma concentration is necessary. On the other hand, the central reactivation effect exists $(9,13,14)$. It is known from other results that the inhibition and reactivation of $\mathrm{AChE}$ in the brain is selective for different OP and following administration of the reactivators to nerve agentintoxicated animals, reactivation of $\mathrm{AChE}$ in different brain parts was demonstrated $(9,13)$. The ability of oximes to penetrate the blood brain barrier was confirmed by Sakurada et al. (116).

There were and are some attempts to synthesize new reactivators with the aim of making them universal or more effective especially against soman or tabun inhibited AChE either in the past (for a review, see 9,63) or presently (78-82). A number of alternative oximes have been shown to be significantly more effective and have a broader spectrum of action than the pralidoxime and several of these may be as or more effective than HI-6 (80-82) (Fig. 8). However, the results obtained up to now are not of interest for introducing them into medical practice. It can be concluded that currently available oximes (pralidoxime, methoxime, obidoxime) are sufficient for therapy of poisonings with OP but they are not very effective against nerve agent (especially soman) poisoning. The H-oximes (HI-6, Hlö-7, in some cases methoxime) appear to be very promising antidotes against nerve agents including soman. However, there is no universal oxime suitable for antidotal treatment of poisoning with all $\mathrm{OP} /$ nerve agents.

Seizures should be prevented and treated when they occur. Against convulsions caused by OP/nerve agents, anticonvulsants were studied empirically. These studies were not carried out only for the treatment of seizures. The control of seizures is strongly associated with protection against lethality and brain pathology (122). Different results were obtained using different anticonvulsants such as barbiturates, hydantoins, local anesthetics, calcium channel blockers, sometimes perspective, however, benzodiazepines were chosen as the most effective $(9,93)$. However, anticonvulsant actions also have some anticholinergics (atropine, scopolamine, biperidene, trihexyphenidyle, procyclidine) $(4,9,75)$. The GABA uptake inhibitor tiagabine, the glutamate receptor antagonists (e.g. memantine, antinicotinic mecamylamine, the alpha(2)-adrenergic agonist clonidine) were not very effective $(5,9,121,122)$. Benzodiazepines were effective against soman-induced seizures with the strong synergistic effects when combined with centrally active anticholinergic drugs. Different benzodiazepines were tested (avizafon, clonazepam, diazepam, loprazolam, loraze- 
pam, midazolam,) and the most pronounced antiseizure activity of diazepam and midazolam was demonstrated. Midazolam may be the most effective anticonvulsant after nerve agents exposure, but, despite its efficacy, it has not yet been approved as a drug for OP-induced seizures. It is notable for its water solubility, short-term onset of action, short half-life, and lack of active metabolites (115). Diazepam has been recommended for standard treatment therapy of convulsions caused by $\mathrm{OP} /$ nerve agents, however, midazolam has very similar or better effects $(9,97,115,122)$ and these results have led to a study with nasal administration of this drug (51). All these studies were performed experimentally on animals pretreated with pyridostigmine and treated with atropine and a reactivator (pralidoxime, trimedoxime, HI-6) to eliminate the lethal effects. A complex therapy including all necessary biochemical examination is necessary to prevent complications and chronic health disturbance.

\section{Conclusions}

- Though the mechanism of action of OP/nerve agents is extensively studied, it needs to be elaborated in more detailed way especially in connection with an influence of non cholinergic transmitter systems.

- It is necessary to study the modelling of OP/nerve agents intoxication and the effect of antidotes and prophylactics including all factors involved.

- The relationship between cholinesterases and their functions needs further study for both enzymes (AChE and $\mathrm{BuChE}$ ).

- Obtaining more detailed information regarding the longterm effects of $\mathrm{OP} /$ nerve agents at low doses (concentrations) is necessary.

- There is a need to search new drugs for prophylaxis and treatment. Cholinesterase preparations are of special interest.

- The gene expression profile after OP/nerve agents intoxication needs to be considered in more detailed way.

\section{References}

1. Abernethy MH, George PM, Herron JL, Evans RT. Plasma cholinesterase phenotyping with use of visible-region spectrophotometry. Clin Chem 1986;32: 194-7.

2. Abdel-Rahman A, Shetty AK, Abou-Donia MB. Acute exposure to sarin increases blood brain barrier permeability and induces neuropathological changes in the rat brain: dose-response relationship. Neuroscience 2002;113:721-41.

3. Abou-Donia MB, Lapadula DM. Mechanisms of organophosphorus ester-induced delayed neurotoxicity: Type I and Type II. Ann Rev Toxicol 1990;30: 405-40.

4. Anderson DR, Harris LW, Chang FCT et al. Antagonism of soman-induced convulsions by midazolam, diazepam, and scopolamine. Drug Chem Toxicol 1997;20:115-31

5. Antonijevic B, Stojiljkovic MP, Bokonjic D, Maksimovic M, Nedeljkovic M Effect of memantine on the permeability of the mice blood-brain barrier in soman poisoning. Toxicol Lett 2003;144(Suppl.1):121.

6. Altrunas I, Delibas N, Demirci M, Kiline I, Tamer N. The effects of methidathion on lipid peroxidation and some liver enzymes: role of vitamins $\mathrm{E}$ and $\mathrm{C}$. Arch Toxicol 2002;76:470-3.

7. Aygun D, Doganay Z, Altintop L et al. Serum acetylcholinesterase and prognosis of acute organophosphate poisoning. J Toxicol Clin Toxicol 2002;40:903-10.
8. Bachmann K. Predicting toxicokinetic parameters in humans from toxicokinetic data acquired from three small mammalian species. J Appl Toxicol 1989;9:331-8.

9. Bajgar J. Organophosphates/nerve agent poisoning: mechanism of action, diagnosis, prophylaxis and treatment. Adv Clin Chem 2004;38:151-216.

10. Bajgar J. Biological monitoring of exposure to nerve agents. Brit $\mathbf{J}$ Ind Med 1992;49:648-53.

11. Bajgar J. Cholinesterases and their possible influencing. Voj Zdrav Listy 1998; $67: 1-6$.

12. Bajgar J, Sevelova L, Krejcova G et al. Biochemical and behavioral effects of soman vapors in low concentrations. Inhal Toxicol 2004;16:497-507.

13. Bajgar J. Present views on toxidynamics of soman poisoning. Acta Med (Hradec Kralove) 1996;39:101-5

14. Bajgar J. The influence of inhibitors and other factors on cholinesterases. Sbor Ved Pr LFUK (Hradec Kralove) 1991;34:3-75.

15. Bajgar J. Differential inhibition of the brain acetylcholinesterase molecular forms following soman, sarin and VX intoxication in laboratory rats. Acta Medica (Hradec Kralove) 1997;40:89-94.

16. Bajgar J. Fusek J. Kassa J. Vachek J. Relationship between toxicity and in vivo anticholinesterase potency in nerve agent poisoning. Voj Zdrav Listy 2001;70: $18-20$.

17. Bajgar J. Fusek J. Vachek J. Treatment and prophylaxis against nerve agent poisoning. ASA Newsletter 1994;94-4:10-1.

18. Bajgar J. Prophylaxis against organophosphorus poisoning. J Med Chem Def 2003;1:1-15.

19. Bajgar J, Hak J. Acetylcholinesterase activity and its molecular forms in rectal tissue in the diagnosis of Hirschprung's disease. Clin Chim Acta 1979;93:93-5.

20. Bajgar J, Kassa J, Fusek J. Diagnostic validity of different biochemical parameters following organophosphate poisoning. In: Proceedings from the 6th CBW Protection Symposium Stockholm, Sweden, May 10-15 1998, 1998:185-8.

21. Bajgar J, Michalek H, Bisso GM. Differential reactivation by HI-6 in vivo of Paraoxon-inhibited rat brain acetylcholinesterase molecular forms. Neurochem Int 1995;26:347-50

22. Bajgar J. Portmann R. The treatment of intoxication with selected organophosphates and carbamate: comparison of different therapeutic approaches. In: Proceedings CBMTS - Industry II, The First Congress on Chemical and Biological Terrorism. Dubrovnik 21-27 April 2001, 2001:180-4.

23. Bardin PG, van Eeden SF, Moolman JA, Foden AP, Joubert J.R. Organophosphate and carbamate poisoning. Arch Intern Med 1994;154:1433-41.

24. Benschop HP, de Jong LPA. Toxicokinetics of nerve agents. In: Somani SM, Romano JA, eds. Chemical Warfare Agents: Toxicity at Low Levels, Boca Raton: CRC Press, 2001:25-81.

25. Bonham JR, Attack JR. A neural tube defect specific form of acetylcholinesterase in amniotic fluid. Clin Chim Acta 1983;135:233-7.

26. Brown MA, Kelley AB. Review of health consequences from high-, intermediateand low-level exposure to organophosphorus nerve agents. J Appl Toxicol 1998; 18:393-408.

27. Brown SS, Kalow W, Pilz W, Whittaker M, Woronick CL. The plasma cholinesterases: a new perspectives. Adv Clin Chem 1981;22:1-123.

28. Capacio BR, Shih T-M. Anticonvulsant actions of anticholinergic drugs in soman poisoning. Epilepsia 2001;32:604-15.

29. Chebabo S, Santos M, Albequerque E. Organophosphate sarin, at low concentrations, inhibits the evoked release of GABA in rat hippocampal slices. Neurotoxicology 1999;20:871-2.

30. Cherry N, Mackness M, Durrington P. Paraoxonase (PON1) polymorphisms in farmers attributing ill health to sheep dip. Lancet 2002;359:763-4.

31. Clark MG, Saxena A, Anderson SM et al. Behavioral toxicity of purified human serum butyrylcholinesterase in mice. In: The 4th International CB Medical Treatment Symposium, 28 April-3 May 2002, Spiez, Switzerland, 2002:Abstract No 19.

32. Cowan FM, Shih TM, Lenz DE, Madsen JM, Broomfield CA. Hypothesis for synergistic toxicity of organophosphorus poisoning-induced cholinergic crisis and anaphylactoid reactions. J Appl Toxicol 1996;16:25-33.

33. De Peyster A, Willys WO, Liebhaber M. Cholinesterase activity in pregnant women and newborns. Clin Toxicol 1994;3296:683-96.

34. Doctor BP, Maxwell DM, Saxena A. Preparation and characterization of bioscavengers for possible use against organophosphate toxicity. In: m-CB Medical Treatment Symposium, 26-30 May 1997, Hradec Kralove, 1997:17-8.

35. Doctor BP, Saxena A, Clark MG et al. Scavenger protection against organophosphates by human serum butyrylcholinesterase. In: The 4th International CB Medical Treatment Symposium, 28 April-3 May 2002, Spiez, Switzerland, 2002: Abstract No 24.

36. Dolezal P, Vachek J, Hrabalek A. In vitro transdermal permeation of a cholinesterase reactivator HI-6. In: Brain RK, Walters KA, eds. Perspectives in percutaneous penetration, Cardiff: STS Publishing, 1988;6A:84.

37. Du Toit PW, Muller FO, van Tonder WM. Experience with the intensive care management of organophosphate insecticide poisoning. S Afr Med J 1981;60:227-9.

38. Eddleston M, Szinicz L, Eyer P, Beuckley N. Oximes in acute organophosphorus pesticide poisoning: a systematic review of clinical trials. QJM Monthly J Assoc Phys 2002;95:275-83 
39. Ellman GL, Courtney DK, Andres V, Featherstone RM. A new and rapis colorimetric determination of acetylcholinesterase activity. Biochem Pharmaco 1961;7:88-95.

40. Fest C, Schmidt KJ. The chemistry of organophosphorus pesticides. Second Revised Edition. Berlin, Heidelberg, New York: Springer-Verlag, 1982.

41. Fidder A, Hulst AG, Noort D et al. Retrospective detection of exposure to organophosphorus anti-cholinesterases: mass spectrometric analysis of phosphylated human butyrylcholinesterase. Chem Res Toxicol 2002;15:582-90.

42. Fleisher JH, Harris LW. Dealkylation as a mechanism for ageing for cholinesterase after poisoning with pinacolyl methylphosphonofluoridate. Biochem Pharmacol 1965;14:641-50.

43. Freeman SE, Dawson RM. Tacrine: a pharmacological review. Prog Neurobiol 1991;36:257-77.

44. Fusek J. Tacrin and its analogues, antidotes against psychotomimetics with anticholinergic effect (in Czech). Voj Zdrav Listy 1977;46:21-7.

45. Fusek J, Bajgar J, Vachek J. The prophylactic antidote against nerve paralytic agents - PANPAL. The Meeting of NATO TG 004 Task Group on Prophylaxis and Therapy of Chemical Agents, 11-13 September 2000, The Hague, The Netherlands, 2000

46. Fusek J, Bajgar J, Herink J, Skopec F. New group of nerve agents: cardiovascula and respiratory effects and blood cholinesterase activity during acute intoxication with 2-dimethylaminoethyl-/dimethylamido)-fluorophosphonate in rats Intern Rev Armed Force Med Serv 1996;69:291-8.

47. Gersl V, Bajgar J, Hrdina R et al. Cholinesterases activities in cardiomyopathy (Daunorubicin cardiomyopathy and Dexrazoxan treated Daunorubicin cardiomyopathy in rabbits).Abstracts, XIIIth National Congress of the Turkish Pharmacological Society with International Participation. Antalya, Turkey, November 5-8, 1996:66

48. Gersl V, Bajgar J, Hrdina R et al. Cholinesterases in Dexrazoxane-treated Daunorubicin cardiomyopathy in rabbits. Gen Physiol Biophys 1999;18:335-46.

49. Gersl V, Bajgar J, Krs O, Hrdina R, Palicka V, Mazurová Y. Changes in cholinesterase activities after Daunorubicin administration to rabbits. Hum Exp Toxicol $1996 ; 15: 834-8$.

50. Gersl V, Bajgar J, Palicka V et al. Influence of drugs without anticholinesterase activity: Daunorubicin in rabbits, Proceedings of the 2nd CB Medical Treatment Symposium 7-12 July 1995, Spiez, Switzerland, 1995:214-6.

51. Gilat E, Goldman M, Lahat E et al. Nasal midazolam as a novel anticonvulsive treatment against organophosphate-induced seizure activity in the guinea pig. Arch Toxicol 2003;77:167-72.

52. Gopalakrishnakone P. Microarray analysis of the human brain cell lines following exposure to a chemical agent, soman. In: Laihia K, ed. Symposium Proceedings NBC 2003, Javaskyla, 2003: 146-7.

53. Green AL. A theoretical kinetic analysis of the protective action exerted by eserine and other carbamate anticholinesterase against poisoning by organophosphorus compounds. Biochem Pharmacol 1983;32:1717-22.

54. Gupta RC, Milatovic D, Dettbarn WD. Depletion of energy metabolites following acetylcholinesterase inhibitor-induced status epilepticus: protection by antioxidants. Neurotoxicolog $y$ 2001;22:271-82.

55. Hadacova V, Klozova E, Pitterova K, Turkova V. The screening of the enzyme and isoenzyme patterns in seeds of Alium cepa cultivar Vsetatska. Biol Plant (Prague) 1981;23:442-8.

56. Herink J, Krejcova G, Bajgar J et al. Cyclosporine inhibits acetylcholinesterase activity in selected parts of the rat brain. Neurosci Lett 2003;339:251-3.

57. Himuro K, Murayama S, Nishiyama K. Distal sensory axonopathy after sarin in toxication. Neurology 1998;51:1195-7.

58. Johnson MK, Glinn P. Neuropathy target esterase (NTE) and organophosphorus-induced delayed polyneuropathy (OPIDP): recent advances. Toxicol Lett 1995;82/83: 459-63.

59. Kadar T, Raveh L, Cohen G et al. Distribution of $3 \mathrm{H}$-soman in mice. Arch Toxicol. 1985;58:45-9.

60. Kalkan S, Erdogan A, Aygoren O, Capar S, Tuncok Y. Pesticide poisonings reported to the drug and poison information center in Izmir, Turkey. Vet Hum Toxicol 2003;45:50-2.

61. Karalliedde L, Wheeler H, Maclehose R, Murray V. Possible immediate and longterm health effects following exposure to chemical warfare agents. Public Health 2000;114:238-48.

62. Kassa J. Non-specific effects of organophosphorus inhibitors of cholinesterases. Voj Zdrav Listy 1998;67:15-9.

63. Kassa J. Review of oximes in the antidotal treatment of poisoning by organophosphorus nerve agents. J Toxicol Clin Toxicol 2002;6:803-16.

64. Kassa J, Bajgar J. The influence of pharmacological pretreatment on efficacy of HI-6 oxime in combination with benactyzine in soman poisoning in rats. Hum Exp Toxicol 1996;15:383-8

65. Kassa J, Cabal J, Bajgar J, Szinicz L. The choice: HI-6, pralidoxime or obidoxime against nerve agents? ASA Newslett 1997;97-4:16-8

66. Kassa J, Frankova K, Hoder P, Patocka J. A comparison of the efficacy of cholinolytics atropine and biperiden (Akineton) in combination with HI-6 on cholinergic and stressogenic effects of soman in rats. Homeostasis 1996;37:135-6.
67. Kassa J. Fusek J. The influence of of anticholinergic drug selection on the efficacy of antidotal treatment of soman poisoned rats. Toxicology 2000;154:67-73.

68. Kassa J, Fusek J, Bajgar J. The importance of PANPAL pretreatment for survival of rats poisoned with supralethal dose of soman. In: m-CB Medical Treatment Symposium, 26-30 May 1997, Hradec Kralove”, Abstracts, 1997:21-2.

69. Kassa J. Pecka M. Tichy M et al. Toxic effect of sarin in rats at three months following single or repeated low-level inhalation exposure. Pharmacol Toxicol 2001;88:209-12

70. Kassa J, Vachek J. Bajgar J, Fusek J. A combination of pyridostigmine with anticholinergic drugs: effective pharmacological pretreatment of soman-poisoned mice. ASA Newslett 2001;84:16-9.

71. Khan S, Hemalatha R, Jeyaseelan L, Oomen A, Zachariah A. Neuroparalysis and oxime efficacy in organophosphate poisoning: a study of butyrylcholinesterase. Human Exp Toxicol 2001;20:169-74.

72. Khodakovskaya OA, Vodolazskaya NA, Glukhova LD et al. Early diagnostics of delayed neurotoxicity. Toxicol Lett 2003;144(Suppl.1):133.

73. Kim YB, Cheon KC, Hur GH et al. Effects of combinational prophylactics composed of physostigmine and procyclidine on soman induced lethality, seizures and brain injuries. Env Toxicol Pharmacol 2002;11:15-21.

74. Kobayashi H, Li Z, Yamataka A et al. Acetylcholinesterase distribution and refractory constipation - a new criterion for diagnosis and management. Pediatr Surg Int 2002;18:349-53.

75. Koplovitz I, Schulz S, Shutz M et al. Combined anticonvulsant treatment of somaninduced seizure. J Appl Toxicol 2001;21:S53-S5.

76. Koponen H. Riekkinen PJ. Cerebrospinal fluid acetylcholinesterase in patients with dementia associated with schizophrenia or chronic alcoholism. Acta Psychiat Scand 1991;83:441-3.

77. Krejcova G. Kassa J. Neuroprotective efficacy of pharmacological pretreatment and antidotal treatment in tabun-poisoned rats. Toxicology 2003;185:129-39.

78. Kuca K, Bielavsky J, Cabal J, Bielavska M. Synthesis of a potential reactivator of acetylcholinesterase - 1-(4-hydroxyiminomethylpyridinium)-3-(carbamoylpyridinium) propane bromide. Tetrahedron Lett 2003;44:3123-5.

79. Kuca K, Bielavsky J, Cabal J, Kassa J. Synthesis of a new reactivator of tabun-inhibited acetylcholinesterase. Bioorg Med Chem Lett 2003;13:3545-7.

80. Kuca K, Kassa J. A comparison of the ability of a new bispyridinium oxime - 1 (hydroxyiminomethylpyridinium)-4-(carbamoylpyridinium)butane dibromide and currently used oximes to reactivate nerve agent-inhibited rat brain acetylcholinesterase by in vitro methods. J Enzyme Inhib Med Chem 2003;18:529-35.

81. Kuca K, Cabal J, Kassa J. A comparison of the efficacy of a bispyridinium oxime - 1,4-bis-(2-hydroxyiminomethylpyridinium) butane dibromide and currently used oximes to reactivate sarin, tabun or cyclosarin-inhibited acetylcholinesterase by in vitro methods. Die Pharmazie 2004;59:795-8

82. Kuca K, Sevelová-Bartosova L, Krejcova-Kunesova G. In vitro reactivation of acetylcholinesterase inhibited by cyclosarin using bisquaternary pyridinium aldoximes K005, K033, K027 and K048. Acta Medica (Hradec Kralove) 2004;47: $107-9$.

83. Lallement G, Baille V, Baubichon D et al. Review of the value of huperzine as pretreatment of organophosphate poisoning. Neurotoxicology 2002;23:1-5.

84. Lehre KP, Hassel B. The role of glutamate transporters in soman poisoning. The meeting of NATO TG 004 Task Group on Prophylaxis and Therapy of Chemical Agents.4-7 November 2002, Oslo, Norway, 2002.

85. Lenz DE, Broomfield AA, Cook LA. Development of immunoassay for detection of chemical warfare agents. Immunochem Technol Environ Applic ACS Symp Series 1999;657:77-86.

86. Little PJ, Scimeca JA, Martin BR. Distribution of /H3/diisopropylfluorophosphate, /H3/soman, /H3/sarin, and their metabolites in mouse brain. Drug Metab Disp 1988; 16:515-20.

87. Lockridge O, Masson P. Pesticide and susceptible populations: people with butyrylcholinesterase genetic variants may be at risk. Neurotoxicology 2000;21 113-26.

88. Lotti M. Organophosphorus compounds. In: Spencer PS, Schaumburg HH, eds Experimental and Clinical Neurotoxicology", $2^{\text {nd }}$ ed., New York: Oxford University Press, 2000 pp. 898-925.

89. Lotti M,. Moretto A. Promotion of organophosphate induced delayed polyneuropathy by certain esterase inhibotors. Chem Biol Interact 1999;119-120:519-24.

90. Luo CY, Leader H, Radic Z et al. Two possible orientations of the HI-6 molecule in the reactivation of organophosphate/inhibited acetylcholinesterase. Biochem Pharmacol 2003;66:387-92.

91. Malik GM, Mubarik M, Romshoo GJ. Organophosphorus poisoning in the Kashmir Valley, 1994 to 1997. N Engl J Med 1998;338:1998-178.

92. Masopust J. Clinical biochemistry of ciliary ducts. Part 2. Tests for bile production and excretion, proteosynthesis, and detoxification (in Czech). Biochem Clin Bohemoslov 1983;12:363-76

93. Marrs TC, Maynard RL, Sidell FR. Chemical warfare agents. Toxicology an treatment. Chicester, New York, Brisbane, Toronto, Singapore: J. Wiley and Sons., 1996.

94. Massoulié J, Pezzementi L, Bon S, Krejci E, Vallette FM. Molecular and cellular biology of cholinesterases. Progr Neurobiol 1993;41:31-91. 
95. Maxwell DM, Lenz DE, Groff WA, Kaminskis A, Froehlich HL. The effect of blood flow and detoxification on in vivo cholinesterase inhibition by soman in rats. Toxicol Appl Pharmacol 1987;88:66-76.

96. McDonough JH. Animal models of nerve agent intoxication and treatment of human nerve agent casualties: Identification of key variables for immediate therapy. The meeting of NATO TG 004 Task Group on Prophylaxis and Therapy of Chemical Agents.4-7 November 2002, Oslo, Norway, 2002.

97. McDonough JH, McMonagle J, Copeland T, Zoeffel D, Shih TM. Comparative evaluation of benzodiazepines for control of soman-induced seizures. Arch Toxicol 1999:73:473-8.

98. Mc Donough JH, Zoeffel LD, McMonagle J, Copeland TL, Smith CD, Shih TM. Anticonvulsant treatment of nerve agent seizures: anticholinergics versus diazepam in soman-intoxicated guinea pigs. Epilepsia 2000;38:1-14.

99. Meshulam Y, Cohen G, Chapman S, Alkalai D, Levy A. Prophylaxis against organophosphate poisoning by sustained release of scopolamine and physostigmine. J Appl Toxicol 2001;21(Suppl.1):S75-S8.

100. Moore DH, Bioscavengers as antidotes for organophosphorus (OP) agents. In Proceedings of the 2nd CB Medical Treatment Symposium, 7-12 July 1996, Spiez, Switzerland, 1996:330-49.

101. Morita H, Yanagisawa T, Nakajima $M$ et al. Sarin poisoning in Matsumoto, Japan. Lancet 1995;346:290-3.

102. Musser G. Better killing through chemistry. Sci Am 2001;285:20-1.

103. Nagao M, Takatori T, Matsuda Y, Nakajima M, Iwase H, Iwadare K. Definitive evidence for the acute sarin poisoning in diagnosis in the Tokyo subway. Toxicol Appl Pharmacol 1997;144:198-203.

104. Nakajima T, Sato S, Morita H, Nakajima T. Sarin poisoning of a rescue team in the Matsumoto sarin incident in Japan. Occup Environ Med 1997:54:697-701.

105. Noort D, Benschop HP, de Jong LPA. Methods for retrospective detection of exposure to toxic scheduled chemicals: an overview. Voj Zdrav Listy 2001;70:14-7.

106. Noort D, Hulst AG, Plattenburg DHJM, Polhuijs M, Benschop HP Quantitative analysis of O-isopropyl methylphosphonic acid in serum samples of Japanese citizens allegedly exposed to sarin: Estimation of internal dose. Arch Toxicol 1998;72:671-5.

107. Noort D, Benschop HP, Black RM. Biomonitoring of exposure to chemical warfare agents: a review. Toxicol Appl Pharmacol 2002;184:116-26.

108. Ohbu S, Yamashina A, Takasu N. Sarin poisoning in Tokyo subway. South Med J 1997;90:587-93.

109. Ohtomi S, Takase M, Kunagoi F. A clinical experience in Japan Self Defence Force (JSDF) Central Hospital. Intern Rev Armed Force Med Serv 1996;69:97-102.

110. Okomura T, Suzuki K, Fukuda A. The Tokyo subway sarin attack. Disaster menagement. Part 2: hospital response. Acad Emerg Med 1998;5:618-24.

111. Patocka J, Kassa J. Huperzine A - prospective prophylactic antidote against organophosphate warfare agent poisoning. ASA Newslett 1999;99-2:16-9.

112. Patočka J, Kuča K, Jun D. Acetylcholinesterase and butyrylcholinesterase important enzymes of human body. Acta Med (Hradec Kralove) 2004;47 215-30.

113. Perry RH, Wilson ID, Bober MJ et al. Plasma and erythrocyte acetylcholinesterase in senile dementia of Alzheimer type. Lancet 1982;1:174-5.

114. Polhuijs M, Langenberg JP, Benschop HP. New method for retrospective detection of exposure to organophosphorus anticholinesterases: application to alleged sarin victims of Japanese terrorists. Toxicol Appl Pharmacol 1997; 146:156-61.

115. Rotenberg JS, Newmark J. Nerve attacks on children: diagnosis and management. Pediatrics 2003;112:648-58.

116. Sakurada K, Matsubara K, Shimizu K et al. Pralidoxime iodide (2-PAM) penetrates across the blood-brain barrier. Neurochem Res 2003;28:1401-7.

117. Saxena A, Doctor BP, Sun W et al. HuBChE: a bioscavenger for protection against organophosphate chemical warfare agents. US Army Med Dept 2004;PB 8/04/10:23-9.

118. Sevelova L, Bajgar J, Saxena A, Doctor BP. Protective effect of equine butyrylcholinsterase in inhalation intoxication of rats with sarin: determination of blood and brain cholinesterase activities. Inhal Toxicol 2004;16:531-6.

119. Sevelova L, Vachek J. Effect of methoxime combined with anticholinergic, anticonvulsant or anti-HCN drugs in tabun-poisoned mice. Acta Med (Hradec Kralove) 2003;46:109-12.

120. Shapira S, Kadar T, Cohen G, Chapman S, and Raveh L. Effects of CBDP and MEPQ on the toxicity and distribution of $/ \mathrm{H} 3 /$-soman in mice. Arch Toxicol 1990;64:663-8.

121. Shih TM, Penetar DM, McDonough JH, Romano JA, King JM. Age-related differences in soman toxicity and in blood and regional cholinesterase activity. Brain Res Bull 1990;24:429-36.

122. Shih TM, Duniho SM, McDonough JH. Control of nerve agent-induced seizures is critical for neuroprotection and survival. Toxicol Appl Pharmacol 2003;188:69-80.
123. Silveire CL, Eldefrawi AT, Eldefrawi ME. Putative M2 muscarinic receptors of rat heart have high affinity for organophosphorus anticholinesterases. Toxicol Appl Pharmacol 1990;103:474-81.

124. Slizova D, Bajgar J, Krs O, Pospisilova B. Changes of the rat liver microcirculation following sublethal intoxication with soman. Voj Zdrav Listy (Suppl) 1997;66:39.

125. Slizova D, Krs O, Bajgar J, Pospisilova B. Changes in microvascularization of some rat organs following soman poisoning. Sb Ved Pr LFUK (Hradec Kralove) 1995;38:115-22.

126. Solberg Y, Belkin M. The role of excitotoxicity in organophopshporous nerve agents central poisoning. TIPS 1997;18:183-5.

127. Soreq H, Gnatt A, Loewenstein Y, Neville LF. Excavations into the active sitegorge of cholinesterase. TIBS 1992;17:353-8.

128. Sungur M, Guven M. Intensive care management of organophosphate insecticide poisoning. Crit Care 2001;5:211-5.

129. Sweeney R, Maxwell D. A theoretical expression for the protection associated with stoichiometric and catalytic scavengers in a single compartment model of organophosphorus poisoning. The meeting of NATO TG 004 Task Group on Prophylaxis and Therapy of Chemical Agents.4-7 November 2002, Oslo, Norway. 2002.

130. Talbot BG, Anderson DR, Harris LW, Zarbrough LW, Lennox WJ. A comparison of in vivo and in vitro rates of ageing of soman-inhibited erythrocyte acetylcholinesterase in different animal species. Drug Chem Toxicol 1988;11:289-395

131. Tonkopii V. Structure and efficiency of carbamates as drugs for prophylaxis against OP poisoning. In: Laihia K, ed. Symposium Proceedings, NBC 2003 , Jyvaskyla, 2003: 140-1

132. Tonkopii V. Oxidative stress in the mechanism of organophosphates neurotoxicity. Toxicol Lett 2003;144(Suppl.1):132.

133. Tryphonas LK, Clement J. Soman toxicity: morphogenesis of CNS and heart lesions. In: Poceedings of the CB MTS, CIBIAC, ASA, Batelle, Edgewood USA, NC Lab Spiez, Switzerland, 2.25-2.26,1995.

134. Vachek J, Gersl V, Fusek J, Krs O, Skopec F, Bajgar J. Toxicities of O-alkyl S (2-dialkylaminoethyl) methyl phosphonothiolates (V-compounds). Acta Med (Hradec Kralove) 1996;39:67-71.

135. Van Helden HPM, Bueters TJH. Protective activity of adenosine receptor antagonists in the treatment of organophosphate poisoning. TIPS 1999;20:438-41.

136. Van der Schans MJ, Noort D, Fidder A, Degenhardt CEAM, Benschop HP, Langenberg JP. Retrospective detection of exposure to organophosphorus anticholinesterases: fluoride reactivation and mass spectrometric analysis of phosphylated human butyrylcholinesterase. The meeting of NATO TG 004 Task Group on Prophylaxis and Therapy of Chemical Agents.4-7 November 2002, Oslo, Norway, 2002

137. Ward TR, Ferris DJ, Tilson HA, Mundy WR. Correlation of anticholinesterase activity of a series of organophosphates with their ability to compete with agonist binding to muscarinic receptors. Toxicol Appl Pharmacol 1993;122:300-7.

138. Weissmann-Brenner A, David A, Vidan A, Hourvitz A. Organophosphate poisoning: a multihospital survey. Isr Med Assoc J 2002;4:573-6.

139. Whittaker M. Plasma cholinesterase variants and the anaesthesist. Anaesthesia 1980; 35:174-97.

140. Worek F, Mast U, Kiderlen D, Diepold C, Eyer P. Improved determination of acetylcholinesterase activity in human whole blood. Clin Chim Acta 1999;288:73-90.

141. Worek F, Reiter G, Eyer P, Szinicz L. Reactivation kinetics o acetylcholinesterase from different species inhibited by highly toxic organophosphates. Arch Toxicol 2002;76:523-9.

142. Yokoyama K, Araki S, Murata K et al. Chronic neurobehavioral and central autonomic nervous system effects in Tokyo subway sarin poisoning. J Physiol 1998;92:317-23.

143. Yoshida T. Toxicological reconsideration of organophosphate poisoning in relation to the possible nerve-gas sarin-poison disaster happened in Matsumoto-city, Nagano. Jap J Toxicol Environ Hlth 1994;40:486-97.

Submitted December 2004.

Accepted February 2005.

Doc. MUDr. Jiři Bajgar, DrSc., University of Defence,

Faculty of Military Health Sciences,

Department of Toxicology,

Třebešská 1575, 50001 Hradec Králové, Czech Republic.

e-mail: bajgar@pmfhk.cz 